\title{
Pro-environmental behavior and morality: An economic model with heterogeneous preferences
}

\author{
Charles Ayoubi ${ }^{\mathrm{a}}$, Boris Thurm ${ }^{\mathrm{b}}$ \\ ${ }^{a}$ Chaire en économie et management de l'innovation, Ecole Polytechnique Fédérale de Lausanne (EPFL), CH-1015 \\ Lausanne, Switzerland \\ ${ }^{b}$ LEURE Laboratory, Ecole Polytechnique Fédérale de Lausanne (EPFL), CH-1015 Lausanne, Switzerland
}

\begin{abstract}
Some individuals voluntarily engage in costly pro-environmental actions although their efforts have limited direct benefits. This paper proposes a novel economic model with heterogeneous agents explaining why. Each agent has a homo moralis type of preference, which combines selfishness and morality. Morality is modeled here as the payoff an agent receives if all other agents act like her. Our model builds on extant literature showing that homo moralis preferences have an evolutionary advantage to better evaluate the behavioral motives of agents. Shedding light on how people respond not only to economic but also moral incentives, we contribute to the ongoing policy debate on the design of efficient environmental policies.
\end{abstract}

Keywords: Morality, Heterogeneous agents, Pro-environmental behavior, Social dilemma, Environmental policy

JEL classification: D60, H23, Q50

\section{Introduction}

Individuals often perform environmentally friendly actions at their own cost and even though their efforts have little impact on environmental quality. However, the propensity to act in favor of the environment varies widely across individuals and countries. This diversity has been observed in many contexts such as recycling efforts (Bruvoll et al., 2002) or the willingness to pay a premium to get green electricity (Sundt and Rehdanz, 2015) and sustainable food (Moon et al., 2002). This paper aims to better understand why some individuals voluntarily engage in these socially beneficial actions while others do not. That understanding aims at helping policymakers design effective environmental policies.

The homo oeconomicus type of preference fails to explain environmentally-friendly behaviors. If individuals were only selfish, they would prefer the cheaper, "dirty" option. More interestingly, when

Email addresses: charles.ayoubi@epfl.ch (Charles Ayoubi), boris.thurm@epfl.ch (Boris Thurm)

We are indebted to Jörgen Weibull, Ingela Alger, Nick Netzer, Dominique Foray, Philippe Thalmann, and Martin Nowak for their invaluable advice. We also thank Damien Ackerer, Sophia Ding, and the participants at the 25th Annual Conference of the European Association of Environmental and Resource Economists (EAERE), the HERUS EPFL Seminar series and the Gerzensee Alumni Seminar 2019 for their helpful comments and suggestions. The research leading to these results has received funding from the European Union's Horizon 2020 research and innovation programme under grant agreement No 730459 (Project EU Calculator: Trade-offs and pathways towards sustainable and low-carbon European). Any opinions and conclusions expressed herein are those of the authors. 
the action of each individual has a negligible impact on environmental quality, altruistic motives cannot explain these behaviors either. For instance, in the context of climate change, each individual effort to decrease greenhouse gas emissions has an insignificant impact on global emissions, and thus no effect on the well-being of others, i.e. on what drives altruism. By contrast, the homo moralis preference, recently put forward by Alger and Weibull $(2013,2016)$, is a good candidate to understand pro-environmental actions since morality consists in considering what happens when all others do the same action. As shown by Awad et al. (2020), individuals exhibit very different propensities to be moral and this diversity is favored by evolution (Ayoubi and Thurm, 2020).

Building on these observations, we design a simple framework with heterogeneous moral agents involved in a social dilemma, where each individual action has no effect on the total contribution. ${ }^{1}$ Our model sheds light on the motives behind pro-environmental behaviors and on the determinants of the level of cooperation in a population. By analyzing the influence of individuals' beliefs on their decisions, we also show why financial incentives could fail in some cases and we offer policy recommendations to promote environmental-friendly behaviors.

Although there are many empirical studies documenting individuals' willingness to engage in pro-environmental actions, there are few theoretical models explaining why they do so. Most of the literature relies on the concept of "warm-glow", which reflects the idea that individuals get a positive utility from doing an action that is perceived as "good" by the society (Andreoni, 1989, 1990). ${ }^{2}$ For instance, Abbott et al. (2013) examine recycling efforts by including the time spent recycling in the household's utility function. However, this modeling approach is ad-hoc and lacks theoretical foundations. Brekke et al. (2003) and Nyborg et al. (2006) incorporate self-image in individuals' utility, such that the morally superior (green) alternative yields a self-image benefit. Nevertheless, they assume that all individuals are identical.

The rest of the paper is organized as follows. In Section 2 we introduce the model. In Section 3, we analyze why some individuals cooperate in social dilemmas and we estimate the level of cooperation in the population. In Section 4, we investigate how individuals' perception alter their decisions. In Section 5, we provide some applications to the purchase of green electricity, of electric vehicles and of sustainable food to illustrate how our model can be applied and extended in a variety of contexts. In Section 6, we examine the effectiveness of policies to foster pro-environmental behaviors. Finally, we recap our findings and we discuss the limitations of our model in Section 7.

\section{Model}

In this section, we present the model and the main definitions. We consider a large population made of a continuum of individuals $i \in I=[0,1]$ involved in a social dilemma (Section 2.1). Individuals have homo moralis preferences and the population is heterogeneous, i.e. individuals have different degrees of morality (Section 2.2).

\section{$2.1 \quad$ Social dilemma}

In a social dilemma, the society is better-off if all individuals cooperate (strategy C). However, each individual has an incentive to defect (strategy D). With only pure strategies, the strategy set

\footnotetext{
${ }^{1}$ The literature often refers to the notion of "public goods" instead of "social dilemma". We favor here the term "social dilemma" to avoid the confusion with public goods experiments in which individuals' choices modify the total contribution.

2 "Warm-glow" is frequently called "impure altruism".
} 
is therefore $X=\{C, D\}$. For all individuals $i \in[0,1]$, we call $x_{i} \in[0,1]$ the level of cooperation of individual $i$. In others words, $x_{i}=1$ if individual $i$ cooperates and $x_{i}=0$ if she defects. The strategy set can then alternatively be written $X=\{0,1\}$. We can then define the (average) cooperation share in the population $\bar{x}=\int_{i \in I} x_{i} d \mu$, with $\mu$ a density measure for the population I. Thus, $\bar{x}$ represents the share of cooperators in the population.

Assumption 1 (Atomicity). Since the population is large, the average level of cooperation in the population is unaffected by the action of a single individual:

$$
\forall j \in I: \quad \bar{x}=\int_{i \in I} x_{i} d \mu=\bar{x}_{-j}=\int_{I-\{j\}} x_{i} d \mu
$$

This property is called atomicity.

For any cooperation share $\bar{x} \in[0,1]$, an individual $i$ playing $x_{i} \in\{0,1\}$ gets a material payoff $\pi_{i}\left(x_{i}, \bar{x}\right)$, where we assume $\pi_{i}:\{0,1\} \times[0,1] \rightarrow \mathbb{R}$ to be continuous and differentiable in $\bar{x}$ for all individuals $i \in I$. In other words, the payoff of an individual $i$ depends both on her strategy $\left(x_{i}\right)$ and on the others' strategies, through the share $\bar{x}$ of individuals cooperating in the population. Moreover, the setting of a social dilemma implies three main assumptions:

Assumption 2 (Cooperation share and individual payoff). Individuals' payoffs are strictly increasing with the cooperation share:

$$
\forall i \in I, \forall \bar{x} \in[0,1], \forall x_{i} \in\{0,1\}: \quad \partial \pi_{i}\left(x_{i}, \bar{x}\right) / \partial \bar{x}>0
$$

Assumption 3 (Social Benefit of Cooperation). Individuals get a strictly greater payoff if everybody cooperates than if everybody defects, i.e.:

$$
\forall i \in I: \quad \pi_{i}(C, 1)>\pi_{i}(D, 0)
$$

Assumption 4 (Individual incentive to Defect). For any value of the cooperation share, each individual is better-off by defecting instead of cooperating:

$$
\forall i \in I, \forall \bar{x} \in[0,1], \quad \pi_{i}(D, \bar{x})>\pi_{i}(C, \bar{x})
$$

An illustration of the social dilemma defined is given in Figure 1.

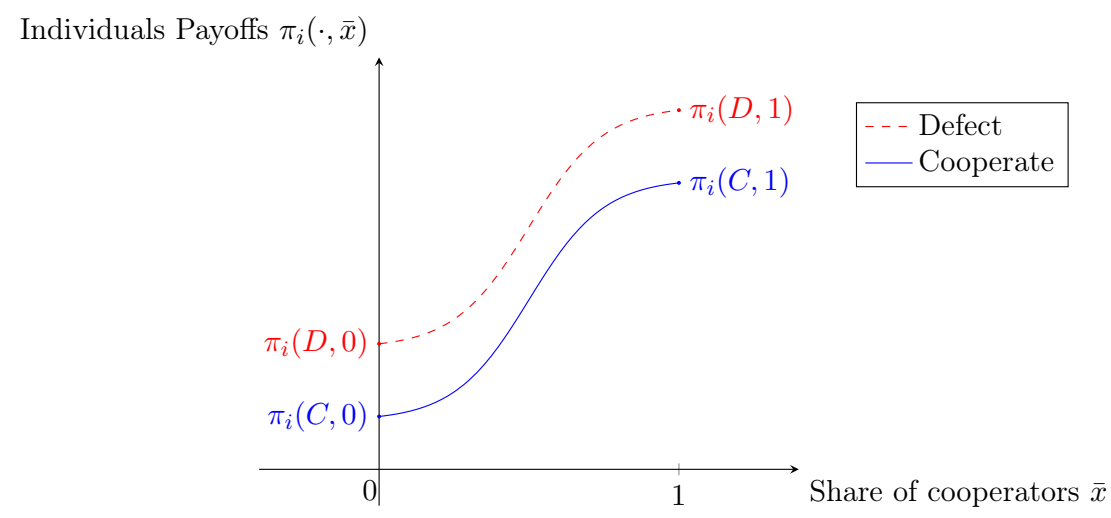

Figure 1: Illustrative Social Dilemma

In the analysis (Section 3), we will see that two key variables drive the decisions of individuals. The first is the individual cost of cooperating: 
Definition 1 (Individual cost). For all $i \in I$, we call individual cost $I C_{i}$ the difference in the material payoff between cooperating and defecting for a given cooperation share $\bar{x}$ :

$$
I C_{i}(\bar{x})=\pi_{i}(D, \bar{x})-\pi_{i}(C, \bar{x})
$$

The individual cost $I C_{i}$ is the individual cost of cooperating (or incentive to defect) of individual $i \in[0,1]$. Assumption 4, implies that for all $i \in I$ and for any $\bar{x} \in[0,1], I C_{i}(\bar{x})>0$.

Second, the social benefit will play a key role:

Definition 2 (Social benefit). For all $i \in I$, we call social benefit $S B_{i}$, the difference in the material payoff of individual $i$ between a situation of full cooperation in the population and a situation of no cooperation:

$$
S B_{i}=\pi_{i}(C, 1)-\pi_{i}(D, 0)
$$

The social benefit of individual $i S B_{i}$ is the difference between her payoff if she cooperates in a population of cooperators and her payoff if she defects in a population of defectors. From Assumption 3 , we know that for all $i \in I, S B_{i}>0$.

Finally, we introduce a particular case which offers an interesting framework in the analysis:

Definition 3 (Uniform Cost-Benefit). We will say that the cost-benefit structure is uniform when the values of individual cost and social benefit are the same for all individuals in the population and independent of the average cooperation in the population $\bar{x}$ :

$$
\begin{aligned}
& \forall i \in I, \bar{x} \in[0,1]: \quad I C_{i}(\bar{x})=I C \\
& \forall i \in I: \quad S B_{i}=S B
\end{aligned}
$$

\subsection{Population}

Individuals are utility maximizers and they all have a homo moralis type of preference. An individual $i$ with a homo moralis preference maximizes a convex combination of her classical selfish payoff, with a weight $\left(1-\kappa_{i}\right)$, and of her "moral" payoff, defined as the payoff she would get if everybody plays like her, with a weight $\kappa_{i}$ :

Definition 4 (Homo moralis). An individual is a homo moralis if her utility function is of the form:

$$
u_{\kappa_{i}}\left(x_{i}, \bar{x}\right)=\left(1-\kappa_{i}\right) \cdot \pi_{i}\left(x_{i}, \bar{x}\right)+\kappa_{i} \cdot \pi_{i}\left(x_{i}, x_{i}\right)
$$

where $\kappa \in[0,1]$ is her degree of morality.

If $\kappa_{i}=0$, the individual is homo oeconomicus (fully selfish), and if $\kappa_{i}=1$, the individual is called homo kantiensis (fully moral) from the name of the German philosopher Immanuel Kant. Indeed, individuals homo kantiensis fully endorse the first formulation of Kant (1870) categorical imperative: "Act only according to that maxim whereby you can, at the same time, will that it should become a universal law.".

There are several theoretical and empirical evidence suggesting that individuals are moral. Alger and Weibull $(2013,2016)$ recently demonstrated that a particular kind of homo moralis arises endogenously as the most favored preference by evolution in a model of preference evolution under incomplete information and assortative matching. Previously, Bergstrom (1995) also proved the 
evolutionary stability of a "semi-Kantian" utility function (a homo moralis with morality coefficient one half) in the special case of symmetric interactions between siblings. Miettinen et al. (2017) have shown that homo moralis has a higher explanatory power than other social preferences in a sequential prisoners' dilemma. Finally, (Ayoubi and Thurm, 2020) have established that homo oeconomicus and homo kantiensis individuals can coexist and be favored by evolution in a prisoner's dilemma. They have also shown that heterogeneous populations are more robust than homogeneous population.

Broadening this diversity, we consider a population of homo moralis with different degrees of morality $\kappa_{i} \in[0,1]$. More precisely, we assume that the individuals' degrees of morality are independently drawn from a given distribution $F($.$) with density f($.$) and support [0,1]$. In other words, Nature assigns a degree of morality $\kappa_{i} \in[0,1]$ to each individual by picking from a given distribution. Using the definitions of the cumulative distribution function (CDF) $F($.$) and the probability density$ function $(\mathrm{PDF}) f($.$) , we have:$

$$
\forall i \in I, \forall k \in[0,1]: \quad P\left(\kappa_{i} \leq k\right)=F(k)=\int_{0}^{k} f(t) d t
$$

We will often assume that the individuals' degree of morality follow a Beta distribution, $\kappa \sim$ $\operatorname{Beta}(a, b)$, with $a>0$ and $b>0$ the shape parameters. The Beta distribution has two major advantages. First, its support is $[0,1]$, hence corresponding to the domain of definition of the morality coefficient $\kappa$. Second, it allows a large flexibility through its two parameters. Most of the common distributions with a $[0,1]$ support can in fact be represented as a Beta distribution by modulating the two parameters. For instance, when $a=1$ and $b=1$, the degrees of morality are uniformly distributed, i.e. Beta $(1,1) \sim \mathrm{U}(0,1)$. Some examples of Beta distribution are illustrated in Figure 8.

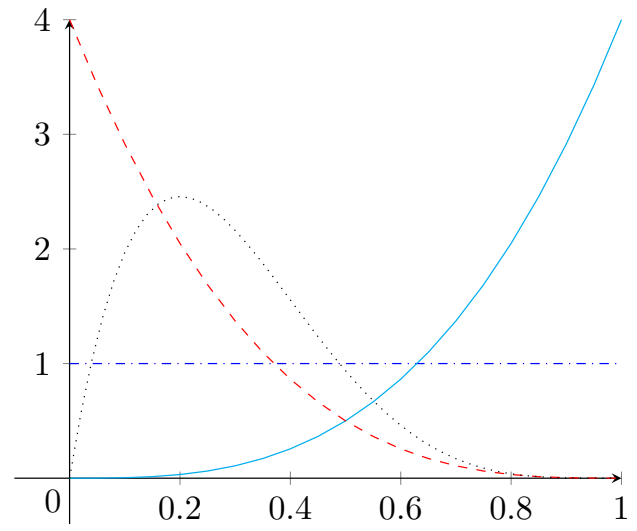

(a) Probability density function

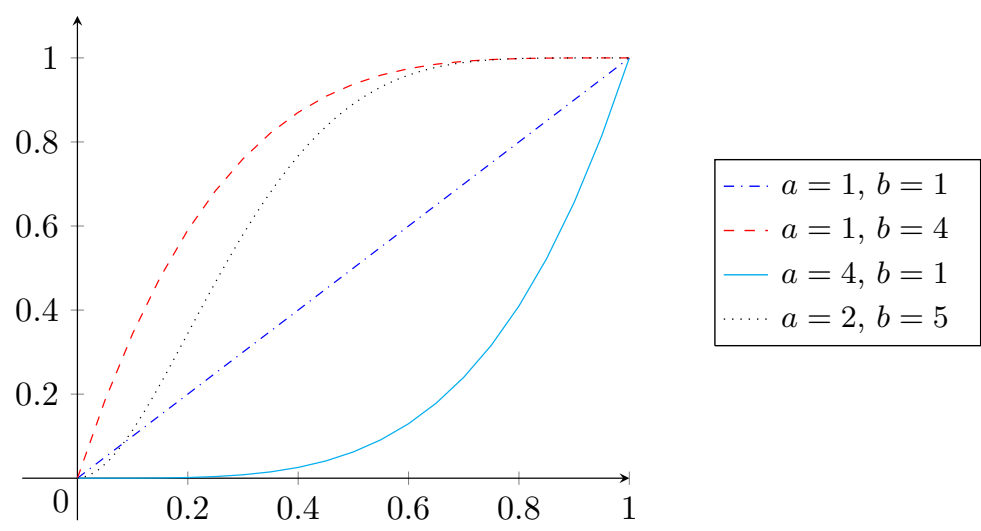

(b) Cumulative distribution function

Figure 2: Distribution of degrees of morality in the population depending on Beta distribution shape parameters

The mean of a beta distribution is $a /(a+b)$. Thus, an increase in $a$ increases the expected degree of morality while an increase in $b$ decreases the expected degree of morality in the population. Finally, the $\mathrm{CDF}$ of the beta distribution, noted $F_{\beta(a, b)}($.$) follows:$

$$
F_{\beta(a, b)}(x)=\frac{\int_{0}^{x} t^{a-1}(1-t)^{1-b} d t}{\int_{0}^{1} t^{a-1}(1-t)^{1-b} d t}
$$

. In particular, we have:

$$
\begin{aligned}
& \forall x \in[0,1], \quad F_{\beta(1, b)}(x)=1-(1-x)^{b} \\
& \forall x \in[0,1], \quad F_{\beta(a, 1)}(x)=x^{a}
\end{aligned}
$$


Having defined all the ingredients in our model, we carry on with the analysis.

\section{Why do some individuals cooperate in a social dilemma?}

We first analyze why some individuals cooperate and others do not in a social dilemma (Section 3.1). Then, we derive the implications for the average level of cooperation in a population (Section 3.2). Finally, we discuss how peer-effect influence the level of cooperation (Section 3.3).

\subsection{Individual cooperation}

For a given cooperation share $\bar{x}$, when they cooperate, homo moralis individuals get utility:

$$
u_{\kappa_{i}}(C, \bar{x})=\left(1-\kappa_{i}\right) \cdot \pi_{i}(C, \bar{x})+\kappa_{i} \cdot \pi_{i}(C, 1)
$$

On the other hand, when they defect, they get:

$$
u_{\kappa_{i}}(D, \bar{x})=\left(1-\kappa_{i}\right) \cdot \pi_{i}(D, \bar{x})+\kappa_{i} \cdot \pi_{i}(D, 0)
$$

Individuals cooperate when their utility is greater when they cooperate than when they defect, i.e. when $u_{\kappa_{i}}(C, \bar{x})-u_{\kappa_{i}}(D, \bar{x}) \geq 0$. We have:

$$
u_{\kappa_{i}}(C, \bar{x})-u_{\kappa_{i}}(D, \bar{x})=\left(1-\kappa_{i}\right) \cdot\left[\pi_{i}(C, \bar{x})-\pi_{i}(D, \bar{x})\right]+\kappa_{i} \cdot\left[\pi_{i}(C, 1)-\pi_{i}(D, 0)\right]
$$

Rewriting this equation with the individual cost of cooperation $I C_{i}(\bar{x})$ (Definition 1 ) and the social benefit $S B_{i}$ (Definition 2):

$$
u_{\kappa_{i}}(C, \bar{x})-u_{\kappa_{i}}(D, \bar{x})=-\left(1-\kappa_{i}\right) \cdot I C_{i}(\bar{x})+\kappa_{i} \cdot S B_{i}
$$

For a selfish homo oeconomicus $\left(\kappa_{i}=0\right)$, we have $u_{0}(C, \bar{x})-u_{0}(D, \bar{x})=-I C_{i}(\bar{x})<0$. Thus, and this comes as no surprise, homo oeconomicus always defects since it is costly to cooperate. On the other hand, for a fully-moral homo kantiensis $\left(\kappa_{i}=1\right)$, we have $u_{1}(C, \bar{x})-u_{1}(D, \bar{x})=S B_{i}>0$. Hence, homo kantiensis always cooperates because they only value what is best for society. More generally, homo moralis cooperates when her degree of morality is high enough:

Theorem 1. For a given cooperation share $\bar{x} \in[0,1]$, a homo moralis cooperates if and only if her degree of morality $\kappa_{i}$ is greater than the threshold $\kappa_{i}^{0}(\bar{x})$ with:

$$
\kappa_{i}^{0}(\bar{x})=\frac{I C_{i}(\bar{x})}{I C_{i}(\bar{x})+S B_{i}} \quad \in(0,1)
$$

Proof. In Appendix A.1

Note that since the payoffs can be different for each individual, so do the individual threshold degree of morality $\kappa_{i}^{0}(\bar{x})$. Thus, two individuals with the same degree of morality could act differently depending on their incentive to defect and on how they benefit from a situation of full cooperation. Moreover, the threshold can evolve with the cooperation share $\bar{x}$. Hence, one individual could cooperate or defect depending on her peers' behavior. We will discuss more this feature in Section 3.3 . 
The degree of morality necessary for cooperation can be low if the social benefit is high in comparison with the individual cost of cooperating: if $S B_{i}>>I C_{i}(\bar{x})$ then $\kappa_{i}^{0}(\bar{x}) \approx 0$. In other words, if the individuals think that the externality associated with defection is high, they will be more inclined to cooperate. On the other hand, when the social benefit is low in comparison with the cooperation cost, only individuals with high degrees of morality will cooperate: if $S B_{i}<<I C_{i}(\bar{x})$ then $\kappa_{i}^{0}(\bar{x}) \approx 1$. This observation is conform with expectations. For instance, individuals are more likely to avoid littering and to recycle when this action requires limited effort (garbage at proximity, process easy to understand, etc.), i.e. when their individual cost of cooperating is low. Similarly, individuals are more likely to support local initiatives to preserve Nature because their social benefit is higher.

\subsection{Level of cooperation in the population}

We have established that individuals cooperate when their degree of morality is high enough. We now analyze what is the equilibrium cooperation share $\bar{x}^{*}$ in the population.

From Theorem 1, the individual threshold for cooperation is $\kappa_{i}^{0}(\bar{x})=I C_{i}(\bar{x}) /\left(I C_{i}(\bar{x})+S B_{i}\right)$ for a given cooperation share $\bar{x}$. Since the degrees of morality are independently drawn from a given distribution $\kappa \sim \mathrm{F}($.$) , the probability of cooperating for each individual i \in I$ is the probability that her individual degree of morality is greater than her threshold $\left(\kappa_{i} \geq \kappa_{i}^{0}(\bar{x})\right)$. We have for all $i \in I$ : $\operatorname{Pr}\left[x_{i}=1\right]=1-F\left(\kappa_{i}^{0}(\bar{x})\right)$. Consequently, the (expected9 equilibrium cooperation share satisfies:

$$
\bar{x}^{*}=\int_{i \in I} \operatorname{Pr}\left[x_{i}=1\right] d \mu=1-\int_{i \in I} F\left(\kappa_{i}^{0}\left(\bar{x}^{*}\right)\right) d \mu
$$

We have the following Proposition:

Proposition 1. Let a population of homo moralis involved in a social dilemma such that the degrees of morality are independently drawn from the distribution $F($.$) . There exists an equilibrium cooperation$ share $\bar{x}^{*} \in[0,1]$ such that $\bar{x}^{*}=1-\int_{i \in I} F\left(\kappa_{i}^{0}\left(\bar{x}^{*}\right)\right) d \mu$.

Proof. In Appendix A.2.

The Proposition proves the existence of an equilibrium cooperation share. Although this might seem obvious, the Proposition is only true because we assumed that the individuals' payoffs are continuous in $\bar{x}$. If this was not the case, there could be a situation where a little group of individuals would always want to deviate so that there does not exist an equilibrium. Moreover, although the Proposition informs about the existence of an equilibrium cooperation share, it tells nothing about its uniqueness. Indeed, there could be more than one equilibrium as we will observe in Section 3.3.

For illustrative purposes, we will study in the following the case of a uniform cost-benefit structure (Definition 3): the individual cost and social benefit are the same for all individuals in the population and independent of the cooperation share $\bar{x}$, i.e. for all $i \in I$ and $\bar{x} \in[0,1], I C_{i}(\bar{x})=I C$ and $S B_{i}=S B$. In this context, we have for all $i \in I \kappa_{i}^{0}=\kappa^{0}=I C /(I C+S B)$ and all individuals with $\kappa_{i} \geq \kappa^{0}$ cooperate. Consequently, the level of cooperation in the population is:

$$
\bar{x}^{*}=1-F\left(\kappa^{0}\right)
$$

Suppose that the population is homogeneous, i.e. all individuals have the same degree of morality $\kappa$. Then, they all make the same decision, i.e. they all defect if $\kappa<\kappa^{0}$ or they all cooperate if $\kappa>\kappa^{0}$. Hence, allowing for a diversity of preferences is necessary to be in line with the empirically observed 
diversity of behaviors. For instance, in a population with a share $\lambda$ of homo kantiensis and $(1-\lambda)$ of homo oeconomicus, the cooperation share $\bar{x}^{*}$ is equal to $\lambda$ since all homo kantiensis cooperate and all homo oeconomicus defect.

More generally, if the individuals' degrees of morality are independently drawn from a Beta distribution, then the level of cooperation in the population is $\bar{x}^{*}=1-F_{\beta(a, b)}\left(\kappa^{0}\right)$. For example, if the degrees of morality are uniformly distributed (i.e. $a=1, b=1$ ), the cooperation share satisfies: $\bar{x}^{*}=1-\kappa^{0}=\frac{S B}{I C+S B}$. If the distribution favors low degree of morality (e.g. $\left.a=1, b=4\right)$, the cooperation share decreases $\bar{x}^{*}=[S B /(I C+S B)]^{4}$. Reciprocally, if the distribution favors high degree of morality (e.g. $a=4, b=1$ ), the cooperation share increases $\bar{x}^{*}=1-[I C /(I C+S B)]^{4}$. These examples are illustrated in Figure 3.

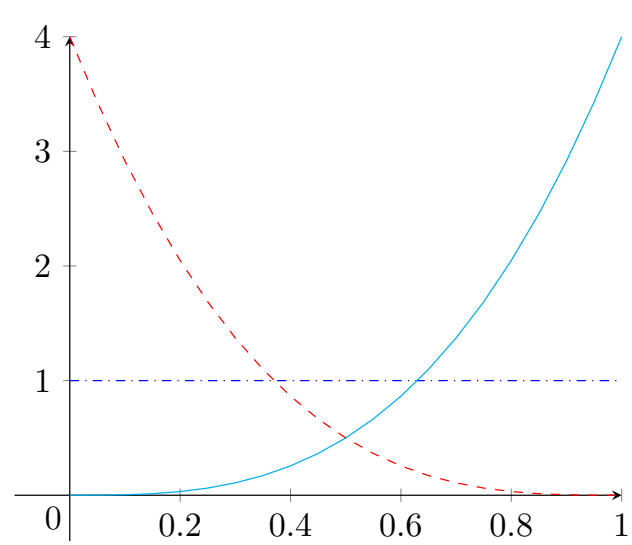

(a) Probability density function

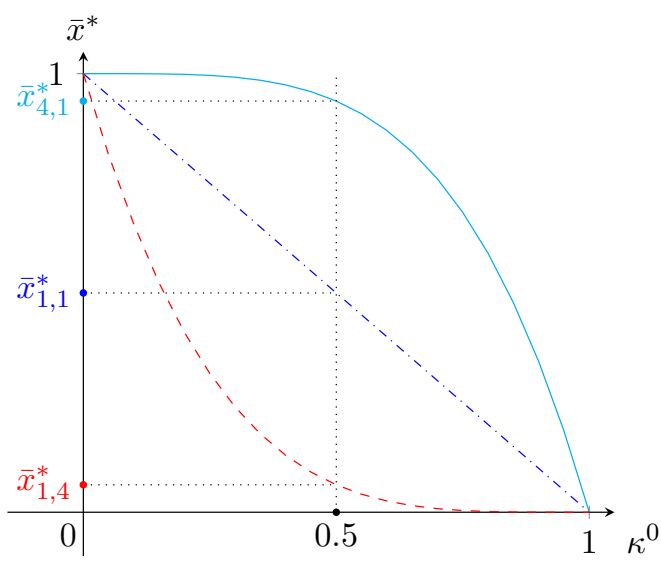

(b) Level of cooperation

Figure 3: Level of cooperation in the population in function of the threshold degree of morality for various distributions of the degrees of morality

Going back to our example on recycling, our model can explain the various recycling rates observed in different countries via two channels. First, one country could have more moral individuals than another. The prevalence of moral individuals is highly dependent on the assortment structure in the population (Ayoubi and Thurm, 2020), i.e. on homophily, which is affected by cultural and geographic conditions among others (McPherson et al., 2001; Zhou, 2011). Second, the threshold degree of morality for cooperation $\kappa^{0}$ can be lower in one country than in another, due to a lower individual cost or a higher social benefit. For instance, designing a clear and understandable recycling process with adequate infrastructure or implementing punishment can decrease the incentive to defect. We will discuss more the role of policy makers in Section 6. However, the story depicted here is still incomplete. In the following, we will discuss how the level of cooperation is influenced by the social structure.

\subsection{Peer effect and social norms}

Individuals are more inclined to cooperate if they are in a cooperative environment (Fischbacher et al., 2001; Frey and Meier, 2004; Kocher et al., 2008). Imitative behaviors have been observed in a variety of context such as environmental and energy conservation (Goldstein et al., 2008; Allcott, 2011) and sustainable food consumption (Vermeir and Verbeke, 2006). Acting as others allow individuals to be accepted in a group and thus gain from network interactions.

Suppose that individuals gain $g$ when sharing the same strategy with others. When they cooperate, the gain is $g \bar{x}$ while they gain $g(1-\bar{x})$ when they defect. We can rewrite the material payoff 
$\pi\left(x_{i}, \bar{x}\right)$ accounting for network interactions:

$$
\pi\left(x_{i}, \bar{x}\right) \quad \text { becomes } \quad \pi\left(x_{i}, \bar{x}\right)+g\left[\bar{x} x_{i}+(1-\bar{x})\left(1-x_{i}\right)\right]
$$

Then, the additional individual cost $\left(I C_{i}(\bar{x})=\pi_{i}(0, \bar{x})-\pi_{i}(1, \bar{x})\right)$ due to network interactions is $g(1-2 \bar{x})$ while the social benefit $\left(S B_{i}=\pi_{i}(1,1)-\pi_{i}(0,0)\right)$ is unchanged. Suppose that the individual cost and the social benefit are independent of the individuals, i.e. for all $i \in I I C_{i}(\bar{x})=I C(\bar{x})$ and $S B_{i}=S B$. Then, assuming that the individual cost depends on the cooperation share only because of network interactions, we can write: $I C_{i}(\bar{x})=I C+g(1-2 \bar{x})$.

In this setting, the threshold degree of morality for cooperation is (Theorem 1):

$$
\kappa_{i}^{0}(\bar{x})=\frac{I C+g(1-2 \bar{x})}{I C+g(1-2 \bar{x})+S B}
$$

And the level of cooperation in the population satisfies $\bar{x}^{*}=1-F\left(\kappa^{0}\left(\bar{x}^{*}\right)\right)$.

We illustrate how peer-effect influences the level of cooperation looking at a few examples. Let $I C=1$ and $S B=1$, the threshold degree of morality for cooperation is then $\kappa_{i}^{0}(\bar{x})=(1+g(1-$ $2 \bar{x})) /(2+g(1-2 \bar{x}))$. We analyze two cases. First, we suppose that the gain from network interactions is relatively low $g=0.1$. Second, we suppose that the gain from network interactions is relatively high $g=10$. Note that in this case, when the cooperation share is greater than $\bar{x}=0.55$, the individual cost of cooperating becomes negative $I C(\bar{x}) \leq 0$. Thus, we are not anymore in a social dilemma and all individuals are better-off by cooperating. In other words, the threshold degree of morality is zero. We look at three different distributions of the degrees of morality (see Figure 8 for a representation of their cumulative and probability density function):

(a) The distribution favors low degree of morality: $a=1, b=4$. The level of cooperation then satisfies $\bar{x}^{*}=\left[1 /\left(2+g\left(1-2 \bar{x}^{*}\right)\right)\right]^{4}$. When the gain from network interactions is relatively small $g=0.1$, there is one equilibrium cooperation share $\bar{x}^{*}=0.0525$. The level of cooperation is low because of the shape of the distribution. On the other hand, when the gain from network interactions is relatively high $g=10$, there are three possible equilibrium cooperation share: the first one is close to zero cooperation, the second is achieved for $\bar{x}^{*} \approx 0.54$ and in the last one there is full cooperation. Since the peer-effect is much stronger than the incentive to defect (without network effect) and than the social benefit, it drives individuals to all defect or all cooperate or to the intermediate situation (see Figure 4a).

(b) The degrees of morality are uniformly distributed: $a=1, b=1$. The level of cooperation then satisfies $\bar{x}^{*}=1 /\left(2+g\left(1-2 \bar{x}^{*}\right)\right)$. When $g=0.1$, the unique equilibrium cooperation share is $\bar{x}^{*}=0.5$. When $g=10$, we still have thee potential equilibria: low cooperation $\bar{x}^{*}=0.1$, medium cooperation $\bar{x}^{*}=0.5$ and full cooperation (see Figure $4 \mathrm{~b}$ ).

(c) The distribution favors high degree of morality: $a=4, b=1$. The level of cooperation then satisfies $\bar{x}^{*}=1-\left[\left(1+g\left(1-2 \bar{x}^{*}\right)\right) /\left(2+g\left(1-2 \bar{x}^{*}\right)\right)\right]^{4}$. Due to the shape of the distribution, there is a unique equilibrium cooperation share in both cases: $\bar{x}^{*} \approx 0.95$ when $g=0.1$ and full cooperation when $g=10$ (see Figure 4c).

These examples first show that peer effect has a strong influence on the level of cooperation. Second, peer effect can also lead to the emergence of multiple equilibria. Note that in Figures 4a and $4 \mathrm{~b}$ for strong peer effect $(g=10)$, the intermediate cooperation equilibrium is unstable. When there is a little deviation to the right, more individuals are willing to cooperate than the actual cooperation share $\left(1-F\left(\kappa^{0}(\bar{x})\right)>\bar{x}\right)$. Conversely, when there is a little deviation to the left, less individuals are willing to cooperate than the actual cooperation share $\left(1-F\left(\kappa^{0}(\bar{x})\right)<\bar{x}\right)$. Thus, strong peer-effect 


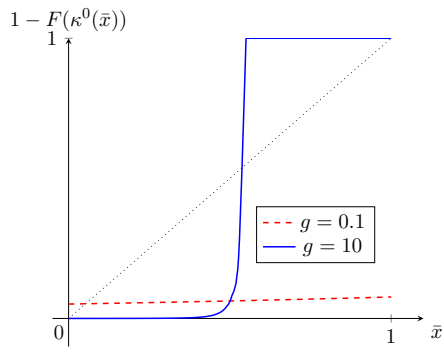

(a) Lowly-moral population $(a=1, b=4)$

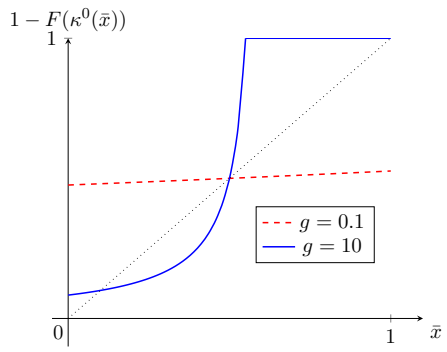

(b) Midly-moral population $(a=1, b=1)$

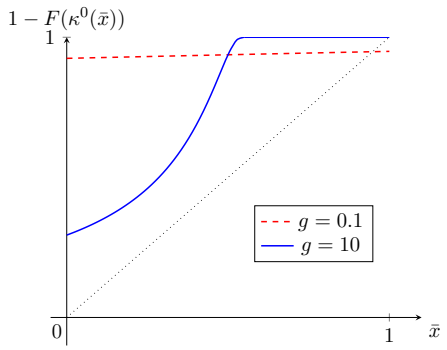

(c) Highly-moral population $(a=4, b=1)$

Figure 4: Influence of peer-effect on the level of cooperation in the population for various distributions of degrees of morality

favors either low or high cooperation share. Even if the distribution of morality, individual cost (without network gain) and social benefit are the same, we could observe completely opposite levels of cooperation. This suggests that the level of cooperation is also determined by social and cultural norms and it could reflect a past dependency.

Moreover, we assumed that network gains were proportional to the cooperation share, as if individuals had interactions with the whole population. In reality, individuals interact in smaller groups. This could lead to the emergence of groups of cooperators and groups of defectors. Since the formation of network is influenced by demography, geography, climate and infrastructure among others, the level of cooperation also depends on the environmental and socio-economic characteristics of countries.

In our framework, we included network interactions as an externality affecting the material payoffs of individuals. Another way to model the higher propensity of individuals to cooperate in cooperative environment would be to add in individuals' utility a reciprocity component as in Levine (1998) or a preference for conformity as in Akerlof (1997). In this setup, it would be as if individuals had internalized the externality when making decisions.

\section{The effect of misperception}

In the model described so far, individuals have a perfect knowledge of the average cooperation share in the population $(\bar{x})$, their individual cost $\left(I C_{i}(\bar{x})\right)$, and social benefit $\left(S B_{i}\right)$ when choosing their strategy. However, this feature is not realistic in all cases and introducing individuals' perception can have major consequences on the model. In this section, we discuss three cases of misperception in our model and the ensuing consequences.

\subsection{Perceived individual cost}

A first case of misperception occurs when the perceived individual cost (noted $\vartheta_{i}\left(I C_{i}(\bar{x})\right)$ ) is different from the actual individual cost $\left(I C_{i}=\pi_{i}(D, \bar{x})-\pi_{i}(C, \bar{x})\right)$ expressed in payoff terms. In this setting, the threshold degree of morality for cooperation becomes:

$$
\kappa_{i}^{0}(\bar{x})=\frac{\vartheta_{i}\left(I C_{i}(\bar{x})\right)}{\vartheta_{i}\left(I C_{i}(\bar{x})\right)+S B_{i}}
$$

Consequently, when the perceived individual cost is greater than the actual individual cost, i.e. when $\vartheta_{i}\left(I C_{i}(\bar{x})\right)>I C_{i}(\bar{x})$, the threshold degree of morality for cooperation increases and individuals have less incentives to cooperate. 
An example of perceived individual cost is linked to switching cost among strategies. If individuals have to make a decision without being assigned a strategy a priori, then they have the same decision cost no matter whether they cooperate or defect, i.e. we are in the case of section 3.1. However, if individuals are assigned to a strategy by default or if they are used to act in a given manner, then it requires effort to switch. Individuals might misjudge the effort needed. For instance, if defection is the default strategy (or action done in the past), then the perceived individual cost can be represented by $\vartheta_{i}\left(I C_{i}(\bar{x})\right)=I C_{i}(\bar{x})+e_{i}$, with $e_{i}$ being the (perceived) individual effort for switching strategy. Thus, the threshold degree of morality for cooperation increases and individuals have less incentives to cooperate:

$$
\frac{\partial \kappa_{i}^{0}(\bar{x})}{\partial e_{i}}=\frac{S B_{i}}{\left(I C_{i}(\bar{x})+e_{i}+S B_{i}\right)^{2}}>0
$$

On the other hand, if individuals are assigned to the cooperation strategy by default, then the perceived individual cost is $\vartheta_{i}\left(I C_{i}(\bar{x})\right)=I C_{i}(\bar{x})-e_{i}$. Hence, the threshold degree of morality for cooperation decreases and individuals have more incentives to cooperate:

$$
\frac{\partial \kappa_{i}^{0}(\bar{x})}{\partial e_{i}}=-\frac{S B_{i}}{\left(I C_{i}(\bar{x})-e_{i}+S B_{i}\right)^{2}}<0
$$

Note that even a selfish homo oeconomicus could cooperate if $I C_{i}(\bar{x})<e_{i}$. Indeed, in this case the perceived individual cost is negative $\vartheta_{i}\left(I C_{i}(\bar{x})\right)<0$ and the individual has more incentives to cooperate.

In both cases the average level of cooperation in the population will be altered based on the default option among the population. Specifically, in the case of uniform cost benefit, we have: $\bar{x}^{*}=1-F\left(\kappa^{0}\right)$. Since the CDF $F($.$) is increasing, the level of cooperation in the population will be higher when the$ default option is cooperation and lower when the default option is defection. We will illustrate this observation in Section 5.1. Therefore, the problem framing and past-dependency matters and could have strong implications on the level of cooperation in the population which underlines the central role played by learning and education for setting the desired individuals' behaviors (see Section 6).

\subsection{Perceived social benefit}

Another case of misperception occurs at the level of the social benefit $\left(S B_{i}=\pi_{i}(C, 1)-\pi_{i}(D, 0)\right)$. For a given cooperation share $\bar{x}$, at the moment of the individuals' decision making, the situations "everybody cooperates" and "everybody defects" are hypothetical, i.e. individuals have to guess what is the social benefit. In some cases, this could be quite challenging. For example, imagine that an individual decides to purchase a new car, having the choice between a conventional fuel-engine or an electric car. Electric mobility coupled with a low-carbon electricity mix emits less greenhouse gas emissions and could decrease urban air pollution but the production of electric vehicles raises concerns on water pollution and materials depletion (Faria et al., 2012, 2013; Hawkins et al., 2013). Furthermore, there are still many uncertainties associated with climate change impacts, and little is known on the climate impacts on catastrophic events, health or biodiversity (Pindyck, 2013). Hence, each individual has to evaluate the social benefit with the best of her knowledge, pondering different objectives. This evaluation is sensitive to her education and her awareness of the problem, and will thus differ from the "true" social benefit.

For each individual, let $\nu_{i}\left(S B_{i}\right)$ be the perceived social benefit of individual $i$. Then, homo moralis cooperates if and only if (Equation 3):

$$
\kappa_{i} \cdot \nu_{i}\left(S B_{i}\right) \geq\left(1-\kappa_{i}\right) \cdot I C_{i}(\bar{x})
$$


Now suppose that the perceived social benefit is negative, i.e. $\nu_{i}\left(S B_{i}\right)<0$. This means that the individual thinks that her payoff when everybody cooperates is lower than her payoff when everybody defects. Then, we are not anymore in a social dilemma, and not matter her degree of morality, the individual defects. Thus, even the fully-moral homo kantiensis defects.

More generally, if an individual underestimates the social benefit, i.e. if $\nu_{i}\left(S B_{i}\right)<S B_{i}$, then the threshold degree of morality for cooperation $\kappa_{i}^{0}(\bar{x})=I C_{i}(\bar{x}) /\left(I C_{i}(\bar{x})+\nu_{i}\left(S B_{i}\right)\right)$ increases. In turn, the probability to cooperate $1-F\left(\kappa_{i}^{0}(\bar{x})\right)$ decreases. If the whole population underestimates the social benefits, i.e. if for all $i \in[0,1] \nu_{i}\left(S B_{i}\right) \leq S B_{i}$, then the expected cooperation share $\bar{x}^{*}=1-\int_{0}^{1} F\left(\kappa_{i}^{0}\left(\bar{x}^{*}\right)\right) d i$ also decreases. We will illustrate this observation in Section 5.1.

Consequently, the social awareness of individuals has a significant impact on their actions and in turn on the level of cooperation in the population. Being knowledgeable of the impacts of human actions on Nature can completely switch individuals' behavior. Conversely, underestimating the impacts of environmentally harmful behavior can lead to socially inefficient situations. Raising the population awareness appears like a necessary action by policy makers and we will further discuss it in Section 6.

\subsection{Perceived level of cooperation}

Even with a perfect knowledge of their individual cost and social benefit, individuals may not know how many cooperators there are in the population, i.e., they misperceive the actual level of cooperation in the population $\left(\bar{x}^{*}\right)$, i.e. individuals do not know exactly how many cooperators there are in the population. This could happen when the externality is not observable (e.g. greenhouse gas emissions) and when the individuals' behavior is their private information (e.g. purchasing or not green electricity). Thus, individuals have to form beliefs $v_{i}(\bar{x})$ about the cooperation share $\bar{x}$ gathering information from the behaviors of individuals in their network or from the media.

In this context, homo moralis cooperates if $\kappa_{i} \geq \kappa_{i}^{0}\left(v_{i}(\bar{x})\right)$ with:

$$
\kappa_{i}^{0}\left(v_{i}(\bar{x})\right)=\frac{I C_{i}\left(v_{i}(\bar{x})\right)}{I C_{i}\left(v_{i}(\bar{x})\right)+S B_{i}}
$$

Now suppose that the individual underestimates the cooperation share (by putting too much emphasis on defecting behaviors for instance), i.e. $v_{i}(\bar{x}) \leq \bar{x}$. In this situation, the individual probability to cooperate is lower if the individual cost of cooperating decreases with $\bar{x}$, for instance under peerpressure or when individuals have a tendency for prosocial conformity (Section 3.3). By contrast, individuals exhibiting anti-conformity are more likely to cooperate when they underestimate the level of cooperation in the population.

At the population scale, if individuals underestimate the level of cooperation (e.g. because of negative news) and if they tend to conform to social norms, then the level of cooperation is lower than under perfect perception. For instance, Frey and Torgler (2007) have shown that tax compliance decreases with perceived tax evasion. This underlines the importance of the framing of news transmission in the society. Insisting only on environmentally-harmful behaviors such as the fraud on emission levels by some firms can deter some individuals from performing environmentally-friendly actions because of their negative perception. On the other hand, putting forward positive actions and cooperative behavior could have surprisingly positive impacts on the environment. 


\section{Applications in environmental and resource economics}

In this section, we first illustrate our model and the effects of misperception with an application on green-electricity purchase (Section 5.1). Then, we look at the adoption of environmentally-friendly products in a dynamic framework (Section 5.2). Finally, we extend the model introducing mixed strategies in the context of resource-use (Section 5.3).

\subsection{Purchasing green electricity}

In many countries, electricity providers offer the option to pay a little more to get "green" electricity, i.e. electricity produced with renewable energy sources (e.g. wind, solar or hydraulic). Indeed, there is a large literature showing the positive willingness to pay for green electricity (e.g. Roe et al., 2001; Hansla et al., 2008; Sundt and Rehdanz, 2015). A recent study conducted among EPFL students and staff members offers some interesting hindsight on this unselfish behavior (Detsouli, 2018). First, $85 \%$ of respondents are willing to pay more to get green electricity, but only $28 \%$ declared they do. This inconsistency suggests that individuals are not aware that this option is available. Actually, most Swiss electricity providers recently changed their standard product so that consumers pay more and get green electricity by default. ${ }^{3}$ If individuals wish to change, they need to contact their electricity provider. This observation highlights the misperception among individuals. Moreover, about $30 \%$ of respondents stated that the share of renewables in their electricity mix is below $15 \%$. But renewables account for about two-third of the Swiss electricity production (SFOE, 2018). Thus, there is a lack of knowledge even though the vast majority of the respondents are sensitive to the environment and willing to make effort. In the following, we present a simple model to shed some lights on these observations and to illustrate the effects of misperception.

Individuals get the utility $V_{i}\left(e_{i}\right)$ and pay the cost $\gamma_{i}\left(e_{i}, \bar{x}\right)$ when they consume the quantity $e_{i}$ of electricity. In addition, they can subscribe to an option to get green electricity (i.e. cooperate) by paying an additional amount $\gamma_{g}\left(e_{i}, \bar{x}\right)$, where we assume that $\gamma_{g}: \mathbb{R} \times[0,1] \rightarrow \mathbb{R}$ decreases with the cooperation share $\bar{x}$ to represent the decrease in price of renewables with their adoption. Note that the potential electricity price change due to renewables integration is already included in the $\operatorname{cost} \gamma_{i}$. We assume that individuals' demand for electricity $e_{i}$ is the same whether they subscribe to the options or not, either because they need $e_{i}$ in their everyday activities or because $\gamma_{g}$ is small in comparison with $\gamma_{i}{ }^{4}$ The production of conventional fossil-fuel electricity emits greenhouse gases contributing to climate change while a greater share of renewables in the electricity mix could increase land and material use (Gagnon et al., 2002). The associated net externality is called $\xi(\bar{x})$. Since the population is large, each individual choice has no effect on the externality. For each cooperation share $\bar{x}$, the payoff to purchase green electricity (C) or not (D) is:

$$
\begin{aligned}
& \pi_{i}(C, \bar{x})=V_{i}\left(e_{i}\right)-\gamma_{i}\left(e_{i}, \bar{x}\right)-\gamma_{g}(\bar{x})-\xi(\bar{x}) \\
& \pi_{i}(D, \bar{x})=V_{i}\left(e_{i}\right)-\gamma_{i}\left(e_{i}, \bar{x}\right)-\xi(\bar{x})
\end{aligned}
$$

Hence, the individual cost of purchasing green electricity is $I C_{i}(\bar{x})=\gamma_{g}\left(e_{i}, \bar{x}\right)$ and the social benefit if everybody cooperates is $S B_{i}=\gamma_{i}\left(e_{i}, 0\right)-\gamma_{i}\left(e_{i}, 1\right)-\gamma_{g}\left(e_{i}, 1\right)+\xi(0)-\xi(1)$. For simplicity, we will assume that the additional cost of purchasing green electricity $\gamma_{g}$ does not depend on the demand for

\footnotetext{
${ }^{3}$ In particular, the "Service Industriel de Lausanne" (SIL) and "Romande Energie" supply most of the Lausanne area and their default product comprises $100 \%$ renewables (see http://paysage-electricite.mynewenergy.ch/ for a map of the default electricity mix by Swiss municipalities).

${ }^{4}$ In Detsouli (2018)'s study, $90 \%$ of respondents indicated that they do not know their electricity consumption.
} 
electricity and that the change in electricity cost $\left(\gamma_{i}\left(e_{i}, 0\right)-\gamma_{i}\left(e_{i}, 1\right)\right)$ is negligible compared to the gain of reducing the externality $(\xi(0)-\xi(1))$. Thus, the individual cost of purchasing green electricity and the social benefit are independent of the individual, i.e. $I C_{i}(\bar{x})=I C(\bar{x})$ and $S B_{i}=S B$. These simplifying assumptions could be relaxed without qualitatively affecting our findings.

Under perfect perception, homo moralis decides to purchase green electricity if:

$$
\kappa_{i} S B \geq\left(1-\kappa_{i}\right) I C(\bar{x}) \quad \Leftrightarrow \quad \kappa_{i} \geq \kappa^{0}(\bar{x})=\frac{I C(\bar{x})}{I C(\bar{x})+S B}
$$

The level of cooperation satisfies $\bar{x}^{*}=1-F\left(\kappa^{0}\left(\bar{x}^{*}\right)\right)$. Let $F$ be a Beta distribution favoring low degree of morality: $a=1, b=4$. Then, the level of cooperation satisfies:

$$
\bar{x}^{*}=\left(\frac{S B}{I C(\bar{x})+S B}\right)^{4}
$$

For instance, when $\gamma_{g}(\bar{x})=0.15-0.1 \bar{x}$ and $S B=1$, we obtain $\bar{x}^{*} \approx 0.75$ (see Figure 5). The level of cooperation is high even though the population is lowly-moral because the individual cost of purchasing green electricity is small in comparison with the benefits of mitigating climate change.

We study now how misperception can affect the level of cooperation:

1. Perceived individual cost (PIC): we assume that the default option is to purchase the standard (dirty) electricity mix. In order to get the green electricity mix, individuals should send a letter. This effort translates into a switching cost $e$, assumed the same for all individuals for simplicity. Thus, the payoff to purchase green electricity becomes: $\pi_{i}(C, \bar{x})=V_{i}\left(e_{i}\right)-\gamma_{i}\left(e_{i}, \bar{x}\right)-\gamma_{g}(\bar{x})-$ $e-\xi(\bar{x})$. In turn, the individual cost is $I C(\bar{x})=\gamma_{g}(\bar{x})+e$ and the social benefit $S B=1-e$ and individuals decide to purchase green electricity if: $\kappa_{i} \geq \kappa_{P I C}^{0}(\bar{x})=\left(\gamma_{g}(\bar{x})+e\right) /\left(\gamma_{g}(\bar{x})+1\right)>$ $\kappa^{0}(\bar{x})$. Because the threshold degree of morality increases, the cooperation share decreases. For example with $e=0.1$, we get $\bar{x}_{P I C}^{*} \approx 0.44$ (see Figure 5).

2. Perceived social benefit (PSB): we assume that there is a lack of awareness regarding climate change, such that the perceived social benefit is $\nu(S B)=0.3$, the same for all individuals for simplicity. For instance, individuals could be more worried about the implementation of wind turbines close to their home than about climate change. Individuals decide to purchase green electricity if $\kappa_{i} \geq \kappa_{P S B}^{0}=\left(\gamma_{g}(\bar{x})\right) /\left(\gamma_{g}(\bar{x})+0.3\right)>\kappa^{0}(\bar{x})$. Because the threshold degree of morality increases, the cooperation share sharply decreases: $\bar{x}_{P S B}^{*} \approx 0.25$ (see Figure 5 ).

3. Perceived level of cooperation $(\mathrm{P} \bar{x})$ : we assume that individuals underestimate the cooperation share such that $v(\bar{x})=\bar{x}^{3}$ for all individuals. This affects the individual cost $I C(\bar{x})=\gamma_{g}\left(\bar{x}^{3}\right)$. In turn, the threshold degree of morality increases $\kappa_{i} \geq \kappa_{P \bar{x}}^{0}(\bar{x})=\gamma_{g}\left(\bar{x}^{3}\right) /\left(\gamma_{g}\left(\bar{x}^{3}\right)+1\right)>\kappa^{0}(\bar{x})$ because $\gamma_{g}$ is a decreasing function. Hence, the cooperation share decreases: $\bar{x}_{P \bar{x}}^{*} \approx 0.62$ (see Figure 5).

Our simple model allows to explain why we can observe high levels of cooperation even in lowlymoral population and even though individuals' behaviors have a negligible impact on the social benefit. Figure 5 also illustrates that individuals' belief and misperception can have a drastic impact. In our example when individuals undervalue the externality (perceived social benefit), about $50 \%$ of individuals do not purchase green electricity anymore. In this case, financial incentives such as taxes and subsidies would have limited impacts, and policy-makers should rely on education instead. Moreover, the problem framing matters: when defection is the default strategy, less than half of the individuals purchase green electricity. By contrast, if we had assumed that the default strategy was cooperation, we would end-up in a case of full-cooperation. Making decisions can be challenging, specially when one has to weigh several criteria or when the outcome is uncertain. The efforts required 


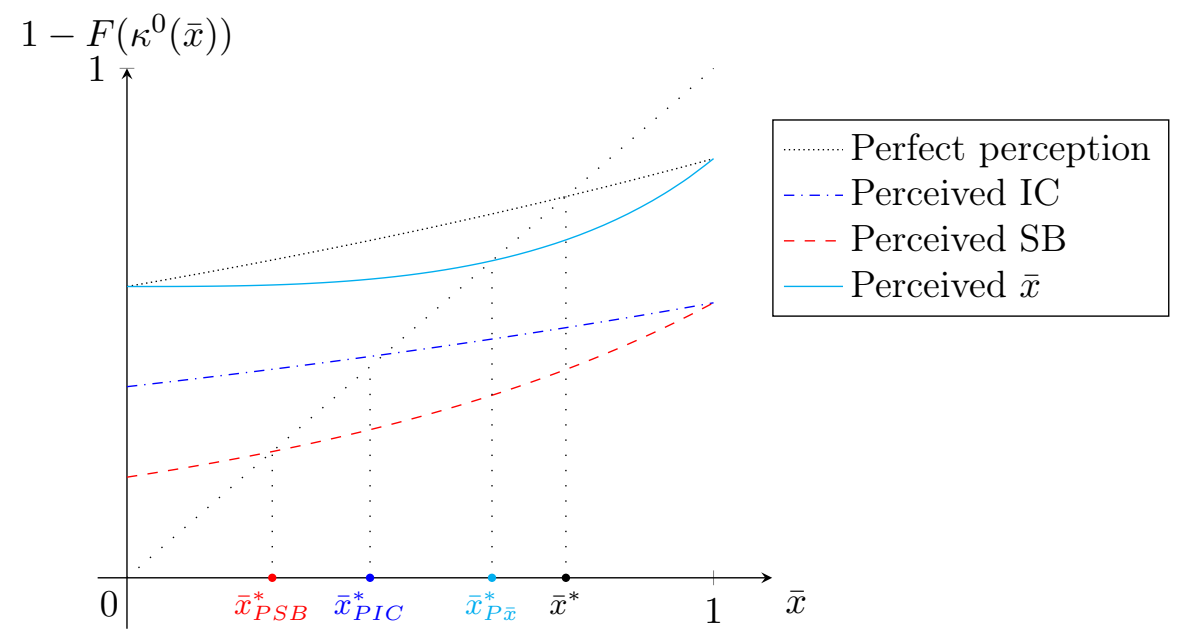

Figure 5: Effects of imperfect information on the share of individuals purchasing green electricity

to decide and to act thus favor the status quo. However, in our context, it seems that individuals are just not aware of their options. In any case, opt in/opt out is an interesting and cheap nudge for policy makers to promote the socially-efficient strategy. We will further discuss the policy implications in Section 6.

\subsection{Adoption of environmentally-friendly technologies}

In this section, we discuss the adoption of environmentally-friendly technologies taking the example of electric vehicles (EV). Electric mobility could decrease environmental and social externalities by reducing greenhouse gas emissions, urban air pollution and noise (Faria et al., 2012, 2013; Hawkins et al., 2013). Thus, the European Commission has implemented in 2009 the Clean Vehicles Directive to promote environmental-friendly vehicles. ${ }^{5}$ However, an ex-post evaluation of the Directive revealed a limited effectiveness and efficiency (Brannigan et al., 2018). There are several barriers to the adoption of EV such as their price, the lack of charging infrastructure and the performance of batteries (Egbue and Long, 2012). In turn, the adoption rates of EV vary between countries and could be partly explained by financial incentives and the charging infrastructure (or lack thereof). Nevertheless, financial incentives are not always successful. For instance, Denmark, Israel, Belgium or the United Kingdom had relatively high financial incentives in 2012, but their EV market share was low (Sierzchula et al., 2014). In the following, we extend our basic model introducing a dynamic framework to better understand these observations.

We assume that each year, a share $\alpha$ of individuals in the population decides to purchase a new vehicle, having the choice between a conventional fuel-engine (defect) or an electric car (cooperate). ${ }^{6}$ Electric vehicles are more expensive, but their cost decreases with their adoption which reflects learning opportunities. This means that the individual cost of cooperating $\operatorname{IC}\left(\bar{x}_{t}\right)$ decreases with the EV share in the total fleet $\bar{x}_{t}$ in year $t \in \mathbb{N}$. We assume that $\operatorname{IC}\left(\bar{x}_{t}\right)=2.5-3 \sqrt{\bar{x}_{t}}$. Note that when $\bar{x}_{t} \geq 0.7$, the individual cost of cooperating is negative. Thus, for a high adoption share, it

\footnotetext{
${ }^{5}$ Directive 2009/33/EC of the European Parliament and of the Council of 23 April 2009 on the promotion of clean and energy-efficient road transport vehicles: https://eur-lex. europa. eu/legal-content/EN/ALL/?uri=CELEX: $32009 \mathrm{~L} 0033$

${ }^{6}$ The share $\alpha$ represents the share of individuals that decide to purchase a new vehicle and have the financial capacity to buy an electric car.
} 
becomes more interesting to purchase an electric vehicle than a conventional fuel-engine car. The EV adoption decreases negative environmental and social externality. We assume that the social benefit is $S B=1$.

Individuals have homo moralis preferences. Thus, when they decide to purchase a new car in year $t$, they prefer EV if their degree of morality is higher than the threshold: $\kappa^{0}\left(\bar{x}_{t}\right)=\max \left[\operatorname{IC}\left(\bar{x}_{t}\right) /\left(\operatorname{IC}\left(\bar{x}_{t}\right)+\right.\right.$ $S B), 0]$. Since the individual cost of cooperating decrease with the EV share $\bar{x}_{t}$, the threshold allowing cooperation also decreases with $\bar{x}_{t}$ and becomes zero when $\bar{x}_{t} \geq 0.7$ (Figure 6). Indeed, EV is then the cheaper option and is attractive even for homo oeconomicus.

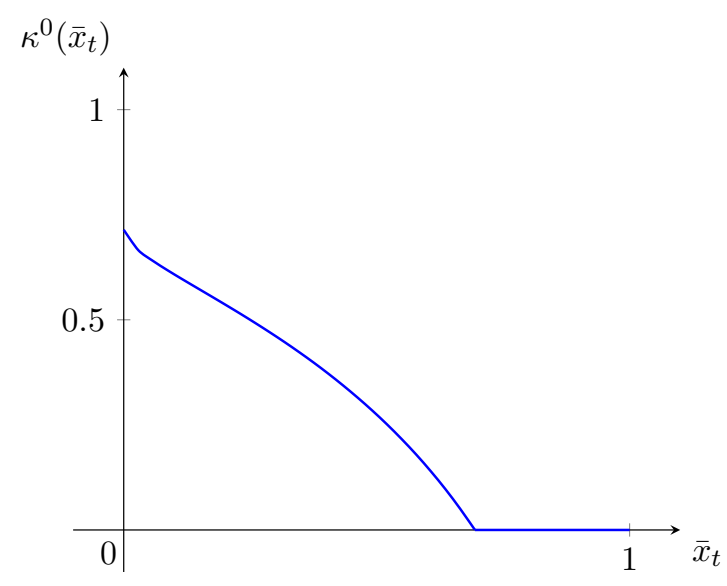

Figure 6: Threshold allowing cooperation in function of EV share in year $t$

Individuals' degrees of morality are independently drawn from a Beta distribution with $a=1$ and $b=4$. Thus, the probability that an individual $i$ purchasing a new car buys an electric vehicle in year $t$ is: $\operatorname{Pr}\left[x_{i}=1\right]=\min \left[\left(S B /\left(I C\left(\bar{x}_{t}\right)+S B\right)\right)^{4}, 1\right]$. Moreover, the probability that an individuals purchases a new car in year $t$ is $\alpha$. Consequently, the EV share in year $(t+1)$ updates to:

$$
\bar{x}_{t+1}=(1-\alpha) \bar{x}_{t}+\alpha \min \left[\left(S B /\left(I C\left(\bar{x}_{t}\right)+S B\right)\right)^{4}, 1\right]
$$

We assume that EV enter the market in year 0 , i.e. $\bar{x}_{0}=0$. Then, only individuals with a high degree of morality $\left(\kappa_{i} \geq \kappa^{0}(0) \approx 0.71\right)$ will install the technology. Thus, the EV share at the beginning of year 1 is low, $\bar{x}_{1} \approx 0.006$. Thanks to the learning effect, the individual cost of cooperating is lower in year 1 than in year 0. In turn, the threshold allowing cooperation decreases and the EV share will increase. This process goes on until the EV share converges. Let $f:[0,1] \rightarrow \mathbb{R}$ and $g:[0,1] \rightarrow \mathbb{R}$ the functions such that $\bar{x}_{t+1}=f\left(\bar{x}_{t}\right)$ and $g(x)=f(x)-x$. The zeros of $g$ are the fixed point of $\left\{\bar{x}_{t}\right\}_{t=0}^{\infty}$. The function $g$ admits three zeros: $\bar{x}_{\infty}^{-} \approx 0.009, \bar{x}^{0} \approx 0.628$ and $\bar{x}_{\infty}^{+}=1$. When $\bar{x}_{t}<\bar{x}^{0},\left\{\bar{x}_{t}\right\}_{t=0}^{\infty}$ converges to $\bar{x}_{\infty}^{-}$. Conversely, when $\bar{x}_{t}>\bar{x}^{0},\left\{\bar{x}_{t}\right\}_{t=0}^{\infty}$ converges to $\bar{x}_{\infty}^{+}$(see Figure 7).

Consequently, the EV share remains very low, reaching the socially-inefficient equilibrium $\bar{x}_{\infty}^{-} \approx$ 0.009. In our framework, the observed diversity of EV market shares across countries can be explained via several channels. First, the distribution of morality could vary from one country to another. Second, the individual cost of cooperating is affected by regulations (e.g. financial incentives) and by socio-economic and geographic characteristics such as infrastructure development, urbanization and the organization of the territory. Lastly, the social benefit, and in turn the decision to cooperate, depends on individuals' perception.

Furthermore, this illustration shows that financial incentives could be quite ineffective. For instance, if the government offers subsidies decreasing the initial individual cost of cooperating by $20 \%$ 


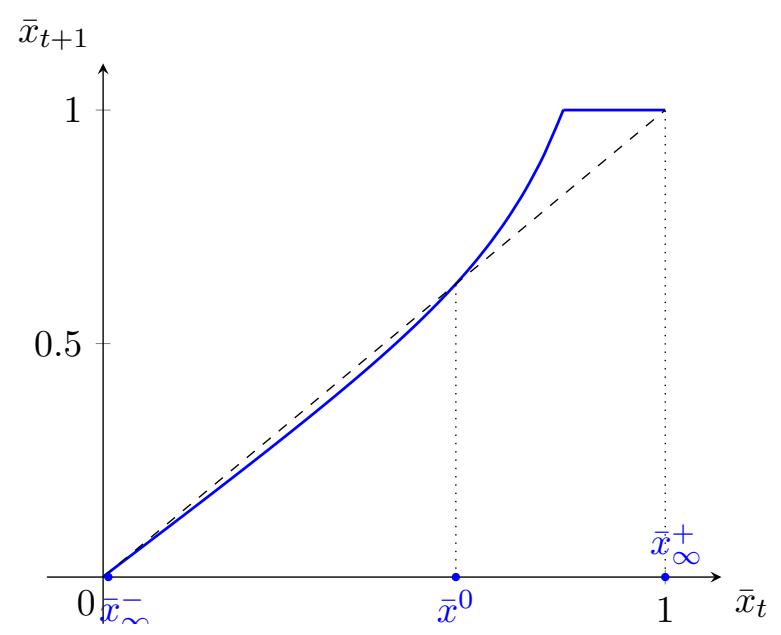

Figure 7: Evolution of EV share due to decreasing adaption cost $(\alpha=0.1)$

$\left(I C\left(\bar{x}_{t}\right)=2-3 \sqrt{\bar{x}_{t}}\right)$, the EV share slightly increases to $\bar{x}_{\infty}^{-} \approx 0.024$. Note that in our framework, the individual cost of cooperating does not include only EV financial cost but also others adoption barriers such as the lack of charging infrastructure. Subsidies decreasing $I C\left(\bar{x}_{t}\right)$ by $20 \%$ could thus represent a much higher share of the EV price. Therefore, only an appropriate mix of policies encompassing subsidies, investment in infrastructure and education program would allow society to reach full cooperation and escape the technological inertia and lock-in (Cowan and Hultén, 1996).

The adoption of environmentally-friendly technologies actually raise several policy dilemmas. ${ }^{7}$ For example, there is a tradeoff between supporting long-term technological alternatives and shortterm solutions, which could slow down long term innovation. Policy makers also have conflicting objectives between favoring a competitive environment and promoting one technology to decrease its cost. This could be especially challenging when there exists several technologies that could achieve the same objective. Finally, the emergence of a new technology is associated with uncertainties about its environmental impacts. Knowledge about these impacts could sometimes only be acquired once the technology is already widely adopted.

Finally, we focused in this example on the growth of the EV share due to a decrease in adoption cost, abstracting from technological improvement. It would be possible to also implement a decrease in EV price through time $(I C(\bar{x}, t))$ and an improvement of battery quality lowering the externality $(\xi(\bar{x}, t))$. As a result, the function $f$ would move up at each time period. When the technology is mature-enough, the only remaining equilibrium then is full adoption.

\subsection{Resource use and sustainable food}

Until now, we have assumed that individuals could either defect or cooperate. But in many situations, the choice is not only black or white. For instance, individuals can decide to purchase sustainable food as a share of their total food basket. ${ }^{8}$ Empirical evidence reveals that the willingness to pay for sustainable food is positive, heterogeneous (Thilmany et al., 2008; Vecchio, 2013; De Magistris et al., 2015), and highly-dependent on peer effect (Vermeir and Verbeke, 2006; Adams

\footnotetext{
${ }^{7}$ See Foray and Grübler (1996) for a detailed description of technology policy dilemmas for environmental issues.

${ }^{8}$ We understand sustainable food in a broad term, encompassing organic and local products, certified fish, and diet changes favoring vegetables and fruits among others.
} 
and Salois, 2010). Since a shift toward sustainable food could improve health, decrease material and energy use, reduce water and soil pollutions using less fertilizers and pesticides and preserve biodiversity (Heller and Keoleian, 2003; Roy et al., 2009), many countries aim to promote organic farming and environmental-friendly fishing. ${ }^{9}$ For example, the European Common Agricultural Plan includes green payment to support sustainable agriculture. Understanding why individuals are willing to purchase more expensive sustainable food is thus crucial to implement effective policies. In the following, we enrich our basic model allowing for mixed strategies in order to better apprehend individuals food choices. This extension is inspired by Alger and Weibull (2017)'s work. In a section of their paper, they study the behavior of homo moralis in a model of two goods, one environmentally neutral and the other environmentally harmful.

We call $x_{i} \in[0,1]$ the share of sustainable food in the total food consumption of individual $i$. When $x_{i}=0$, the individual does not consume sustainable food, i.e. she "defects". When $x_{i}=1$, the individual only consumes sustainable food, i.e. she "cooperates". The average consumption of sustainable food in the population $\bar{x}$ is thus called the cooperation share. We assume atomicity, i.e. a change in sustainable food consumption of individual $i$ does not affect the aggregate consumption of sustainable food:

Assumption 5 (Atomicity). The average level of cooperation in the population is unaffected by the action of a single individual:

$$
\forall i \in I, \forall \bar{x} \in[0,1], \forall x_{i} \in[0,1]: \quad \partial \bar{x} / \partial x_{i}=0
$$

Consuming more sustainable food means that individuals have to do some sacrifices such as consuming less meat or giving up exotic vegetables and fruits. On the other hand, it could procure additional satisfaction thanks to better-quality products or improved health. We represent these effects in the hedonic utility $V_{i}\left(x_{i}\right)$ where we assume that $V_{i}:[0,1] \rightarrow \mathbb{R}$ is continuous and differentiable for all individuals. Moreover, we suppose that purchasing a share $x_{i}$ of sustainable food requires an additional spending $\gamma_{s} x_{i}$ due to loss from trade and costly environmental-friendly production techniques. Finally, the consumption of sustainable food is associated with better environmental conditions, i.e. it decreases the negative externality $\xi(\bar{x})$, with $\xi:[0,1] \rightarrow \mathbb{R}$ is assumed continuous, strictly decreasing and differentiable. Putting it all together, the individuals' payoff $\pi_{i}:[0,1]^{2} \rightarrow \mathbb{R}$ is:

$$
\pi_{i}\left(x_{i}, \bar{x}\right)=V_{i}\left(x_{i}\right)-\gamma_{s} x_{i}-\xi(\bar{x})
$$

Individuals have homo moralis preference:

$$
\begin{aligned}
u_{\kappa_{i}}\left(x_{i}, \bar{x}\right) & =\left(1-\kappa_{i}\right) \cdot \pi\left(x_{i}, \bar{x}\right)+\kappa_{i} \cdot \pi\left(x_{i}, x_{i}\right) \\
& =V_{i}\left(x_{i}\right)-\gamma_{s} x_{i}-\left(1-\kappa_{i}\right) \xi(\bar{x})-\kappa_{i} \xi\left(x_{i}\right)
\end{aligned}
$$

Hence, for a given $\bar{x}$, they solve the following maximizing problem:

$$
x_{i}^{*} \in \arg \max _{x_{i} \in[0,1]}\left\{V_{i}\left(x_{i}\right)-\gamma_{s} x_{i}-\left(1-\kappa_{i}\right) \xi(\bar{x})-\kappa_{i} \xi\left(x_{i}\right)\right\}
$$

\footnotetext{
${ }^{9}$ See for instance the detailed European Action Plan on organic farming https://ec.europa.eu/agriculture/ organic/eu-policy/european-action-plan_en and EU fisheries policies https://ec.europa.eu/fisheries/ reform/.
} 
If an individual defects, then for all $x_{i} \in[0,1], V_{i}(0)-\kappa_{i} \xi(0) \geq V_{i}\left(x_{i}\right)-\gamma_{s} x_{i}-\kappa_{i} \xi\left(x_{i}\right)$. Thus, her degree of morality satisfies:

$$
\kappa_{i} \leq \frac{V_{i}(0)-V_{i}\left(x_{i}\right)+\gamma_{s} x_{i}}{\xi(0)-\xi\left(x_{i}\right)} \quad \forall x_{i} \in(0,1]
$$

Conversely, if an individual cooperates, then for all $x_{i} \in[0,1], V_{i}(1)-\gamma_{s}-\kappa_{i} \xi(1) \geq V_{i}\left(x_{i}\right)-$ $\gamma_{s} x_{i}-\kappa_{i} \xi\left(x_{i}\right)$ so that her degree of morality satisfies:

$$
\kappa_{i} \geq \frac{V_{i}\left(x_{i}\right)-V_{i}(1)+\gamma_{s}\left(1-x_{i}\right)}{\xi\left(x_{i}\right)-\xi(1)} \quad \forall x_{i} \in[0,1)
$$

In particular, if for all $x_{i} \in[0,1] V_{i}\left(x_{i}\right)+\gamma_{s}\left(1-x_{i}\right) \leq V_{i}(1)$ then the individual cooperates no matter her degree of morality since the right-hand side of Equation 6 is negative. This could be the case if the individual loves vegetarian food and pays close attention to her health.

When a mixed strategy $x_{i} \in(0,1)$ is optimal, then:

$$
\frac{\partial V_{i}\left(x_{i}^{*}\right)}{\partial x_{i}}=\gamma_{s}+\kappa_{i} \frac{\partial \xi\left(x_{i}^{*}\right)}{\partial x_{i}}
$$

For example, with $V\left(x_{i}\right)=0.5\left(1+x_{i}-x_{i}^{2}\right), \gamma_{s}=0.5$ and $\xi_{i}(\bar{x})=1-\bar{x}$, we obtain $x_{i}^{*}=\kappa_{i}$.

Then, when the individuals degree of morality are independently drawn from a beta distribution $\kappa \sim \beta(a, b)$, the density of people playing $x_{i}^{*}=\kappa_{i}$ is $f_{\beta(a, b)}\left(x_{i}^{*}=\kappa_{i}\right)$. Thus, the expected cooperation share is $\bar{x}^{*}=\int_{i \in I} x_{i}^{*} f_{\beta(a, b)}\left(x_{i}^{*}\right) d x_{i}^{*}=\int_{i \in I} \kappa_{i} f_{\beta(a, b)}\left(\kappa_{i}\right) d \kappa_{i}$ and is equal to the mean of the beta distribution.

$$
\bar{x}^{*}=\frac{a}{a+b}
$$

For instance, in a lowly-moral population $(a=1, b=4)$, we have $\bar{x}^{*}=20 \%$.

This application illustrates that our basic framework can easily be enriched and that heterogeneous moral population can explain environmental-friendly behaviors in a variety of context. However, our simple model has some substantial limitations. First, we mentioned that peer-effect has a strong influence on food consumption but we did not include it in our example. Introducing peer-effect is of limited complexity but would not lead to an easy analytical solution. Second, and more importantly, we did not incorporate individuals' wealth and the production side, such that income effect is missing and price effects are incorrectly portrayed. A proper analysis would requires a general equilibrium approach. Therefore, this application should be understood as a basis for further research.

Nonetheless, our model offers some interesting insight. In particular, if we focus on local food associated with a decrease in environmental and social externality (e.g. due to less transport or stricter environmental norms), a moral population will have a higher demand for local products than a population of homo oeconomicus. This observation is in line with empirical evidence showing that there is too little international trade and too much intranational trade (McCallum, 1995; Wolf, 2000). This "home bias puzzle" is unexplained by trade cost barriers. While most of the trade literature focuses on the production side and border effects (Evans, 2003; Yi, 2010), Caron et al. (2014) argue that the characteristics of individuals' preferences should be taken into account. Consequently, implementing morality in a trade model could help solving part of the puzzle by better representing the consumer side. 


\section{Policy implications}

In a model with homo oeconomicus agents, individuals are only receptive to financial and regulatory incentives. Introducing heterogeneous moral agents provides new insights on potential policies to promote cooperation. We first discuss the effectiveness of financial instruments in our setting (Section 6.1), before looking at the effects of nudges (Section 6.2), signaling, learning and education (Section 6.3) and urban planning (Section 6.4).

\subsection{On the effectiveness financial instruments}

Financial incentives are widely used to promote environmental-friendly behaviors. ${ }^{10}$ For instance, subsidies are implemented to enhance energy efficiency in buildings (e.g. insulation, efficient boilers and electric appliances), renewable energy installation (e.g. photovoltaic, solar thermal, heat pump) and clean transport (e.g. electric and hybrid cars). The subsidies can be complemented by carbon taxes on fossil fuels and by feed-in premia and tariffs for green electricity. The European Common Agricultural Plan includes green payments to farmers to support crop diversification, maintenance of permanent grasslands and ecological focus areas. In Switzerland, waste management incorporates garbage collection and rubbish bag taxes, and fines as defined by the Environmental Protection Act. In this section, we analyze the effectiveness of financial incentives in promoting cooperative behaviors in our framework. The instrument is effective when it is pursuing the right goal, i.e. it helps increasing the cooperation share.

Let $\tau_{i}$ be a financial incentive. When $\tau_{i}$ is a (lump-sum) tax or a fine, the individual payoff of defecting $\pi_{i}(D, \bar{x})$ becomes $\left(\pi_{i}(D, \bar{x})-\tau_{i}\right)$. When $\tau_{i}$ is a subside, the individual payoff of cooperating $\pi_{i}(C, \bar{x})$ becomes $\left(\pi_{i}(C, \bar{x})+\tau_{i}\right)$. In both cases, the financial incentive decreases the individual cost of cooperating and increases the social benefit: $I C_{\tau i}(\bar{x})=I C_{i}(\bar{x})-\tau_{i}$ and $S B_{\tau i}=S B_{i}+\tau_{i}$, with $I C_{i}(\bar{x})$ and $S B_{i}$ the individual cost and social benefit in the absence of incentives. Under perfect perception, homo moralis cooperates if and only if:

$$
\begin{aligned}
& \kappa_{i} \cdot\left(S B_{i}+\tau_{i}\right) \geq\left(1-\kappa_{i}\right) \cdot\left(I C_{i}(\bar{x})-\tau_{i}\right) \\
\Rightarrow \quad & \tau_{i} \geq\left(1-\kappa_{i}\right) I C_{i}(\bar{x})-\kappa_{i} S B_{i}
\end{aligned}
$$

Note that if individuals are homo oeconomicus, the financial incentive is effective only if $\tau_{i} \geq I C_{i}(\bar{x})$. By contrast, a moral individual needs a lower incentive to adjust her behavior since she includes the social benefit when making her decision. Yet, the financial incentive is ineffective if it is smaller than the threshold $\tau_{i}^{0}=\left(1-\kappa_{i}\right) I C_{i}(\bar{x})-\kappa_{i} S B_{i}$. In particular, a Pigovian tax on the externality would not change individuals' behavior in our setting since they all have a negligible impact on the externality (atomicity assumption). As observed in Section 5.2, the electric-vehicles market share remains low in some countries despite relatively high financial incentives. Similarly, a carbon tax on gasoline has a limited effect on driving behaviors, resulting in a small improvement of the quality of the environment (Sipes and Mendelsohn, 2001). In our setting, these observations can be explained by the high individual cost of cooperating, due to the lack of charging infrastructures for electric vehicles and public transport options among others.

Moreover, financial incentives should be tailored to each individual to be efficient. Our framework suggests that the optimal financial incentive $\left(\tau_{i}^{0}=\left(1-\kappa_{i}\right) I C_{i}(\bar{x})-\kappa_{i} S B_{i}\right)$ depends on the individual

\footnotetext{
${ }^{10}$ The Climate Policy Database provides a list of policies related to climate change mitigation worldwide, see http://climatepolicydatabase.org/; the MURE Database lists energy efficiency policies in Europe, see http: //www.measures-odyssee-mure.eu/.
} 
cost, social benefit and also degree of morality. However, policy makers cannot easily infer the degrees of morality of each individual. Only behaviors can be observed, and not preferences. Still, it is possible to take advantage of the diversity of morality in the population. For instance, one could imagine a transfer mechanism such that individuals with the highest propensity to cooperate cross-subsidize the ones with the lowest. This could take the form of a voluntary environmental tax, the proceeds being used to fund environmental projects. Furthermore, when the individual cost is decreasing with the cooperation share (for instance when peer pressure is strong, see Section 3.3, or in a dynamic settings, see Section 5.2), a financial incentive increases the cooperation share via two channels. First, all individuals with $\tau_{i} \geq \tau_{i}^{0}$ directly adjust their behaviors. Second, since the cooperation share increases, the individual cost decreases and so do the threshold degrees of morality. Hence, even a moderate incentive $\left(\tau_{i}<I C_{i}(\bar{x})\right)$ could lead to a situation of full cooperation.

However, these observations only hold true under perfect perception. Indeed, when individuals overestimate the individual cost or when they underestimate the social benefit or the cooperation share, the financial incentives needed to promote cooperation could be excessively high to cover for the misperception. This observation is in line with empirical evidences showing that individuals question the effectiveness of environmental taxes. Public acceptance depends on beliefs about environmental consequences and on concerns about distributional, competitiveness and employment effects (Thalmann, 2004; Kallbekken and Sælen, 2011; Carattini et al., 2017). Thus, policy makers should better communicate on the environmental, social and economic impacts of taxation. They should also be careful on the instrument design and favor progressive designs, e.g. recycling via lump-sum transfers, such that lower income groups do not pay the burden of the tax. Finally, policy makers could improve trust in the society and remedy a low perception of the cooperation share by increasing financial penalties and controls.

Nonetheless, relying on financial incentives could have major drawbacks if their implementation disrupts individuals' perception. For example, an insufficient tax may send the wrong signal that the externality is fully-compensated. In other words, individuals would no longer consider the social benefit when making a decision, as if they were homo oeconomicus. Furthermore, empirical evidence suggests that individuals are more selfish when they evolve in a monetary environment. For instance, reminding individuals of money decreases helping behaviors (Vohs et al., 2006) and increases endorsement of social inequality (Caruso et al., 2013). In a famous field-study in day-care centers, Gneezy and Rustichini (2000) have also shown that the introduction of a fine for parents arriving late to collect their children significantly increased the number of late-coming parents. Even worse, the effect was not reversible: after the fine was removed, no reduction occurred. These observations suggest that by putting a price on Nature, individuals could leave the "moral sphere" towards the "economic sphere". As a result, the distribution of morality in the population would shift down and the cooperation share would decrease as illustrated in Figure 8. 


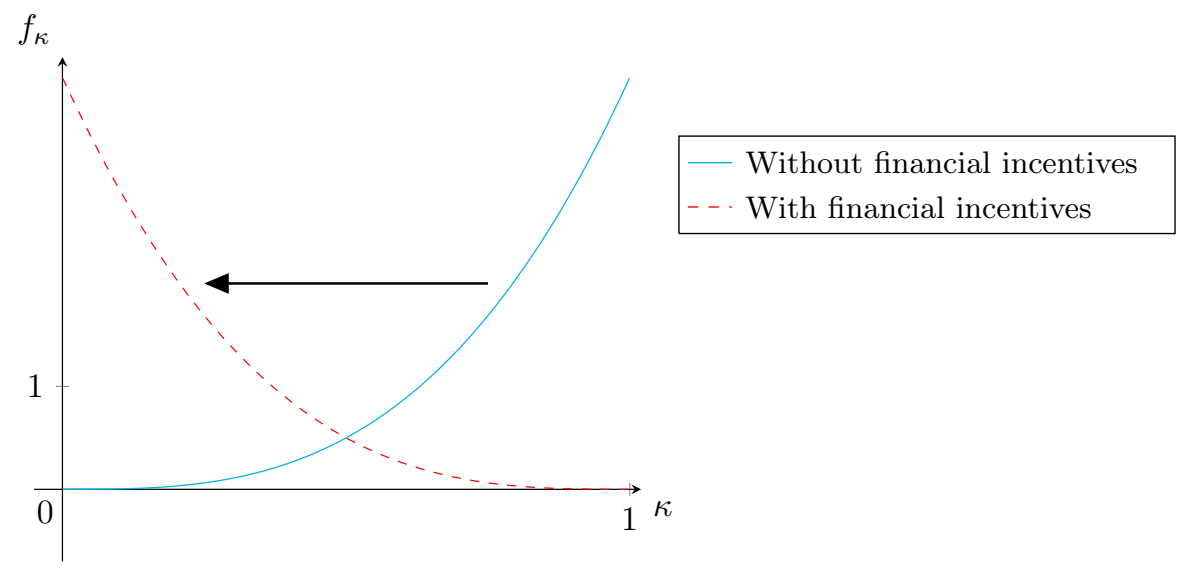

Figure 8: Effect of the introduction of a financial mechanism on the distribution of degrees of morality in the population

\subsection{Nudges}

Thaler and Sunstein (2008, p. 6) defines nudges as an intervention that "alters people's behaviour in a predictable way without forbidding any options or significantly changing their economic incentives". Nudges have received increasing interest because they are cheap, they do not limit individuals' freedom of choice and they are generally well-accepted by citizens (Hagman et al., 2015; Reisch and Sunstein, 2016). ${ }^{11}$ Nudges have also proven effective in a variety of contexts, helping translate the good intentions of individuals into actions (Byerly et al., 2018). For example:

- In a field experiment in a university, the recycling rate of plastic cups has increased from $4 \%$ to almost $100 \%$ by showing a positive message and by increasing the relative size of the recycling garbage (Cosic et al., 2018). Similarly, informing individuals that the majority of them act in an environmentally-friendly way can enhance towels reuse in hotels (Goldstein et al., 2008) while placing signs encourage the use of stairs (Brownell et al., 1980; Blamey et al., 1995).

- The consumption of vegetarian meals increases when the menu favors meat-free dishes (CampbellArvai et al., 2014). Decreasing the default plate size limits food waste (Kallbekken and Sælen, 2013).

- Offering free bus tickets can reduce drivers' negative perception of public transport and promote persistent bus use (Fujii and Kitamura, 2003; Taniguchi and Fujii, 2007; Beirão and Cabral, 2007)

- Expressing vehicles' fuel efficiency in terms of consumption per distance (e.g. liters per 100 kilometers) instead of distance per consumption (miles per gallon) could help to promote the adoption of efficient vehicles by changing individuals' perception (Larrick and Soll, 2008).

- Showing households the electricity consumption of their neighbors in combination with injunctive norms (e.g. smileys to indicate good performance) enables to decrease the electricity consumption. For example, in the United States, the OPOWER program has reduced the electricity consumption by $2 \%$, which is equivalent to a short-run electricity price increase of 11 to $20 \%$ (Allcott, 2011). However, in the absence of injunctive norms there is a risk of a boomerang effect, i.e. the most efficient households actually increase their consumption, another evidence of conformity-driven behavior (Schultz et al., 2007). Finally, this effect is heterogeneous and

\footnotetext{
${ }^{11}$ Even though nudges do not limit the freedom of choice, individuals could still perceive them as intrusive (Hagman et al., 2015) .
} 
depends on individuals' political views (Costa and Kahn, 2013).

- The share of individuals purchasing green electricity increases when the default electricity mix is the green mix (Pichert and Katsikopoulos, 2008), as illustrated in Section 5.1. This effect has also been observed in paper use, energy efficiency and smart grids among others (See Sunstein and Reisch, 2014, for a review of the effects of green defaults).

By contrast with a model assuming homo oeconomicus individuals, our framework allows to explain these observations and why nudges are effective. Indeed, nudges rely on individuals' morality and they modify the perceived individual cost, social benefit and cooperation share. They also take advantage of social norms and of the problem framing. Hence, nudges can be a good complement or substitute to financial incentives when the latter fail. However, properly assess the effects of nudges in our model would require additional information on how nudges influence individuals' perception and the problem framing. Unfortunately, learning about an optimal nudge could be very complex or even impossible (Benkert and Netzer, 2018).

\subsection{Signaling, learning and education}

Instead of relying on financial incentives, policy makers could take advantage of individuals' inclination to contribute voluntarily. One issue hindering individuals' cooperation is the asymmetry of information between producers and consumers. For instance, households have little knowledge about their resource consumption: in Detsouli (2018)'s study, 90\% of respondents indicated that they do not know their electricity consumption (see Section 5.1). Thus, promoting the implementation of smart meters in combination with feedback on the evolution of households' consumption can help enhance energy conservation (Steg, 2008; Hargreaves et al., 2010; Anda and Temmen, 2014) and curb water demand (Willis et al., 2013; Fielding et al., 2013; Sønderlund et al., 2016). Similarly, knowing the environmental externality associated with the purchase of goods might be challenging. Hence, signaling the environmental quality of products can help trigger behavioral changes. For example, eco-labels and certificates can promote energy-efficiency (Banerjee and Solomon, 2003; Brounen and Kok, 2011) and sustainable food (Caswell and Mojduszka, 1996; Teisl et al., 2002; Brécard et al., 2009). However, an abundance of labels could create confusion. To be effective, labels must also be trusted, easily-understood and accessible (Golan et al., 2001; Banerjee and Solomon, 2003). Else, the cost of implementation might outweigh the benefit.

Another issue hampering environmental-friendly behaviors could be the lack of environmental knowledge in the population. As discussed in Section 5.1, a majority of individuals do not know the composition of their electricity mix. Frick et al. (2004) have also shown that Swiss citizens had a poor understanding of greenhouse gas effects, of energy efficiency and of the ozone layer depletion. Increasing the environmental knowledge thanks to education and communication campaigns can support pro-environmental behaviors and lead to better-informed decisions (Bradley et al., 1999; Zsóka et al., 2013). To be effective, the knowledge transmission between experts and the general public requires policy makers to understand what people know. Individuals should also trust the information. In particular, information should be understandable and transparent.

As a drawback, environmental signals and education can only influence the behaviors of the most moral individuals. This could explain the observed gap between environmental knowledge and proenvironmental behaviors (Kuhlemeier et al., 1999; Kollmuss and Agyeman, 2002) and why labels tend to widen differences between consumers (Moorman, 1996). In addition, if the most moral individuals also have the highest environmental knowledge, then education would have a limited effect.

Moreover, misperception is not only due to a lack of environmental awareness or knowledge. Beliefs

are also shaped by social norms, religion or the emotional context. For instance, the willingness to 
pay to save birds following the Exxon Valdez oil spill was independent of the number of birds that could be saved, individuals reacting to "the awful image of a helpless bird drowning, its feathers soaked in thick oil" (Kahneman, 2011, p. 92). ${ }^{12}$ In this case, trying to influence beliefs using rational arguments is condemned to failure. Thus, educational campaigns should also rely on strong symbols that reach individuals' affect, such as pictures showing the rapid decline of glaciers or polar bears stuck on ice floe. The question is then how long this effect can last.

Nonetheless, even if education does not directly or permanently change the perceived social benefit, it could still promote cooperative behaviors by influencing the distribution of morality in the population. Bay-Hinitz et al. (1994) have shown that when children play cooperative games instead of competitive games, selfish and aggressive behaviors decreases. This suggests that the educational system should put more emphasis on cooperation between students and less on competition.

\subsection{Urban planning, infrastructures development and local economy}

An appropriate urban planning and the development of green infrastructures can decrease the (perceived) individual cost and thus favor environmental-friendly behaviors. As argued in Section 5.2 , the lack of charging infrastructure is a hurdle to the development of electric vehicles. Similarly, improving public transport availability and connectivity could foster its use. Walking and cycling can be encouraged by providing close-to-home services (e.g. shopping, schools), by creating parks and recreational areas and by building walking and biking trails and secure parking for bicycles (Sallis et al., 1998; Ogilvie et al., 2007).

In addition, the urban planning can also influence the perception of the social benefit. Indeed, public green spaces contribute towards community attachment (Arnberger and Eder, 2012) and proenvironmental attitudes by enhancing the emotional connection with Nature (Budruk et al., 2009). Hence, green cities could support sustainability not only by improving energy efficiency and resource use, but also by affecting individuals' behaviors.

This vision echoes the architecture ideals "Garden-City" of Ebenezer Howard and "Ville Radieuse" of Le Corbusier. These utopian cities include large green spaces nurturing the connection between humans and Nature and promoting biodiversity. They encourage soft mobility by separating streets and walking paths and by locating services and jobs at a walking distance of homes. The "GardenCity" also aims at achieving local self-sufficiency. For example, food production is located inside the city, fostering waste reuse and limiting transport pollution.

Besides decreasing environmental externality, promoting local exchanges and initiatives has other advantages. First, by increasing the assortment between individuals, it could also increase the morality in the population. Second, while economic globalization might give the impression that resources are abundant and conceal environmental pollution, a more local economy could help individuals understand the effects of their consumption and better apprehend the scarcity of resources.

\section{Conclusion}

We designed a model with heterogeneous moral agents in order to better comprehend individuals' decision making in social dilemmas. Our definitions of morality and of the heterogeneous moral population have a strong theoretical foundation, building on the findings of Ayoubi and Thurm

\footnotetext{
${ }^{12}$ More precisely, the average contribution to save 2'000, 20'000 and 200'000 birds was $\$ 80, \$ 78$ and $\$ 88$ (Kahneman, 2011, p. 92).
} 
(2020) who showed that heterogeneous moral populations are favored by evolution. Our framework can explain why individuals care for Nature and why some of them are willing to contribute voluntarily to environmental protection, even though the impact of their actions on environmental externalities is negligible. We then explored the bias affecting individuals' decision-making such as peer pressure, switching costs and misperception. We illustrated how our model can apply to a variety of contexts and can shed light on several empirical findings. Finally, we discussed the policy implications arguing that financial incentives are not always effective and that policy makers could instead rely on other instruments such as nudges, labels and educational campaigns. They could also target different groups with different policies and rely on a combination of instruments. The effectiveness of policies depend on the socio-economic and geographic characteristics of a country. Hence, there does not exist an optimal instrument independently of the context.

Focusing mainly on the effects of morality and its diversity, our settings abstract from other important determinants of individuals' behaviors. In particular, we did not incorporate individuals' wealth such that income and price effects are incorrectly portrayed by the individual cost of cooperating. Since poorer households might not have the financial capacity to invest in environmental-friendly products and technologies (e.g. electric vehicles, rooftop solar panels, insulation), they also do not have the opportunity to behave morally. Introducing income heterogeneity would be crucial to understand the tradeoff between economic and moral drivers and would bring new insights for policy makers.

Furthermore, we did not include other individuals' motivations such as altruism, empathy, riskaversion and time-preference. This could hold important consequences for instance for the adoption of technologies in the context of climate change. Precisely, climate change impacts are long-term, uncertain and spatially-distributed. Even a highly-moral individual would not make efforts to decrease her greenhouse gas emissions if she has a strong preference for the present since her perceived social benefit is then negligible. Similarly, homo moralis individuals only consider their own social benefit so that they would not act in a socially-responsible way if the impacts only affect others.

Morality is only part of the equation, but an often overlooked one. This paper aims at opening the way for the consideration of moral motives and their diversity in the environmental policy debate. 


\section{References}

Abbott, A., Nandeibam, S., and O'Shea, L. (2013). Recycling: Social norms and warm-glow revisited. Ecological Economics, 90:10-18.

Adams, D. C. and Salois, M. J. (2010). Local versus organic: A turn in consumer preferences and willingness-to-pay. Renewable Agriculture and Food Systems, 25(4):331-341.

Akerlof, G. A. (1997). Social distance and social decisions. Econometrica: Journal of the Econometric Society, pages 1005-1027.

Alger, I. and Weibull, J. W. (2013). Homo moralis - preference evolution under incomplete information and assortative matching. Econometrica, 81(6):2269-2302.

Alger, I. and Weibull, J. W. (2016). Evolution and Kantian morality. Games and Economic Behavior, 98:56-67.

Alger, I. and Weibull, J. W. (2017). Strategic behavior of moralists and altruists. Games, 8(3):38.

Allcott, H. (2011). Social norms and energy conservation. Journal of Public Economics, 95(910):1082-1095.

Anda, M. and Temmen, J. (2014). Smart metering for residential energy efficiency: The use of community based social marketing for behavioural change and smart grid introduction. Renewable Energy, 67:119-127.

Andreoni, J. (1989). Giving with impure altruism: Applications to charity and ricardian equivalence. Journal of Political Economy, 97(6):1447-1458.

Andreoni, J. (1990). Impure altruism and donations to public goods: A theory of warm-glow giving. The Economic Journal, 100(401):464-477.

Arnberger, A. and Eder, R. (2012). The influence of green space on community attachment of urban and suburban residents. Urban Forestry \& Urban Greening, 11(1):41-49.

Awad, E., Dsouza, S., Shariff, A., Rahwan, I., and Bonnefon, J.-F. (2020). Universals and variations in moral decisions made in 42 countries by 70,000 participants. Proceedings of the National Academy of Sciences.

Ayoubi, C. and Thurm, B. (2020). Evolution and heterogeneity of social preferences. Available at SSRN 3672390.

Banerjee, A. and Solomon, B. D. (2003). Eco-labeling for energy efficiency and sustainability: a meta-evaluation of us programs. Energy Policy, 31(2):109-123.

Bay-Hinitz, A. K., Peterson, R. F., and Quilitch, H. R. (1994). Cooperative games: a way to modify aggressive and cooperative behaviors in young children. Journal of Applied Behavior Analysis, 27(3):435.

Beirão, G. and Cabral, J. S. (2007). Understanding attitudes towards public transport and private car: A qualitative study. Transport Policy, 14(6):478-489.

Benkert, J.-M. and Netzer, N. (2018). Informational requirements of nudging. Journal of Political Economy, 126(6):2323-2355. 
Bergstrom, T. C. (1995). On the evolution of altruistic ethical rules for siblings. The American Economic Review, pages 58-81.

Blamey, A., Mutrie, N., and Tom, A. (1995). Health promotion by encouraged use of stairs. BMJ, 311(7000):289-290.

Bradley, J. C., Waliczek, T. M., and Zajicek, J. M. (1999). Relationship between environmental knowledge and environmental attitude of high school students. The Journal of Environmental Education, 30(3):17-21.

Brannigan, C., Luckhurst, S., Kirsch, F., Lohr, E., and Skinner, I. (2018). Ex-post evaluation of directive 2009/33/ec on the promotion of clean and energy efficient road transport vehicles. Technical report, Ricardo Energy \& Environment, TEPR.

Brécard, D., Hlaimi, B., Lucas, S., Perraudeau, Y., and Salladarré, F. (2009). Determinants of demand for green products: An application to eco-label demand for fish in europe. Ecological Economics, 69(1):115-125.

Brekke, K. A., Kverndokk, S., and Nyborg, K. (2003). An economic model of moral motivation. Journal of Public Economics, 87(9-10):1967-1983.

Brounen, D. and Kok, N. (2011). On the economics of energy labels in the housing market. Journal of Environmental Economics and Management, 62(2):166-179.

Brownell, K. D., Stunkard, A. J., and Albaum, J. M. (1980). Evaluation and modification of exercise patterns in the natural environment. The American Journal of Psychiatry.

Bruvoll, A., Halvorsen, B., and Nyborg, K. (2002). Households' recycling efforts. Resources, Conservation and Recycling, 36(4):337-354.

Budruk, M., Thomas, H., and Tyrrell, T. (2009). Urban green spaces: A study of place attachment and environmental attitudes in india. Society and Natural Resources, 22(9):824-839.

Byerly, H., Balmford, A., Ferraro, P. J., Hammond Wagner, C., Palchak, E., Polasky, S., Ricketts, T. H., Schwartz, A. J., and Fisher, B. (2018). Nudging pro-environmental behavior: evidence and opportunities. Frontiers in Ecology and the Environment, 16(3):159-168.

Campbell-Arvai, V., Arvai, J., and Kalof, L. (2014). Motivating sustainable food choices: The role of nudges, value orientation, and information provision. Environment and Behavior, 46(4):453-475.

Carattini, S., Baranzini, A., Thalmann, P., Varone, F., and Vöhringer, F. (2017). Green taxes in a post-paris world: are millions of nays inevitable? Environmental and Resource Economics, 68(1):97-128.

Caron, J., Fally, T., and Markusen, J. R. (2014). International trade puzzles: A solution linking production and preferences. The Quarterly Journal of Economics, 129(3):1501-1552.

Caruso, E. M., Vohs, K. D., Baxter, B., and Waytz, A. (2013). Mere exposure to money increases endorsement of free-market systems and social inequality. Journal of Experimental Psychology: General, 142(2):301.

Caswell, J. A. and Mojduszka, E. M. (1996). Using informational labeling to influence the market for quality in food products. American Journal of Agricultural Economics, 78(5):1248-1253. 
Cosic, A., Cosic, H., Ille, S., et al. (2018). Can nudges affect students' green behaviour? a field experiment. Journal of Behavioral Economics for Policy, 2(1):107-111.

Costa, D. L. and Kahn, M. E. (2013). Energy conservation "nudges" and environmentalist ideology: Evidence from a randomized residential electricity field experiment. Journal of the European Economic Association, 11(3):680-702.

Cowan, R. and Hultén, S. (1996). Escaping lock-in: the case of the electric vehicle. Technological forecasting and social change, 53(1):61-79.

De Magistris, T., Del Giudice, T., and Verneau, F. (2015). The effect of information on willingness to pay for canned tuna fish with different corporate social responsibility (csr) certification: a pilot study. Journal of Consumer Affairs, 49(2):457-471.

Detsouli, M. (2018). Empirical evidence on non-selfish motives underlying the payment of a premium for green electricity. Technical report, EPFL.

Egbue, O. and Long, S. (2012). Barriers to widespread adoption of electric vehicles: An analysis of consumer attitudes and perceptions. Energy Policy, 48:717-729.

Evans, C. L. (2003). The economic significance of national border effects. American Economic Review, 93(4):1291-1312.

Faria, R., Marques, P., Moura, P., Freire, F., Delgado, J., and de Almeida, A. T. (2013). Impact of the electricity mix and use profile in the life-cycle assessment of electric vehicles. Renewable and Sustainable Energy Reviews, 24:271-287.

Faria, R., Moura, P., Delgado, J., and De Almeida, A. T. (2012). A sustainability assessment of electric vehicles as a personal mobility system. Energy Conversion and Management, 61:19-30.

Fielding, K. S., Spinks, A., Russell, S., McCrea, R., Stewart, R., and Gardner, J. (2013). An experimental test of voluntary strategies to promote urban water demand management. Journal of Environmental Management, 114:343-351.

Fischbacher, U., Gächter, S., and Fehr, E. (2001). Are people conditionally cooperative? evidence from a public goods experiment. Economics Letters, 71(3):397-404.

Foray, D. and Grübler, A. (1996). Technology and the environment: an overview. Technological forecasting and social change, 53(1):3-13.

Frey, B. S. and Meier, S. (2004). Social comparisons and pro-social behavior: Testing" conditional cooperation" in a field experiment. American Economic Review, 94(5):1717-1722.

Frey, B. S. and Torgler, B. (2007). Tax morale and conditional cooperation. Journal of Comparative Economics, 35(1):136-159.

Frick, J., Kaiser, F. G., and Wilson, M. (2004). Environmental knowledge and conservation behavior: Exploring prevalence and structure in a representative sample. Personality and Individual Differences, 37(8):1597-1613.

Fujii, S. and Kitamura, R. (2003). What does a one-month free bus ticket do to habitual drivers? an experimental analysis of habit and attitude change. Transportation, 30(1):81-95. 
Gagnon, L., Belanger, C., and Uchiyama, Y. (2002). Life-cycle assessment of electricity generation options: The status of research in year 2001. Energy Policy, 30(14):1267-1278.

Gneezy, U. and Rustichini, A. (2000). A fine is a price. The Journal of Legal Studies, 29(1):1-17.

Golan, E., Kuchler, F., Mitchell, L., Greene, C., and Jessup, A. (2001). Economics of food labeling. Journal of Consumer Policy, 24(2):117-184.

Goldstein, N. J., Cialdini, R. B., and Griskevicius, V. (2008). A room with a viewpoint: Using social norms to motivate environmental conservation in hotels. Journal of Consumer Research, $35(3): 472-482$.

Hagman, W., Andersson, D., Västfjäll, D., and Tinghög, G. (2015). Public views on policies involving nudges. Review of Philosophy and Psychology, 6(3):439-453.

Hansla, A., Gamble, A., Juliusson, A., and Gärling, T. (2008). Psychological determinants of attitude towards and willingness to pay for green electricity. Energy Policy, 36(2):768-774.

Hargreaves, T., Nye, M., and Burgess, J. (2010). Making energy visible: A qualitative field study of how householders interact with feedback from smart energy monitors. Energy Policy, 38(10):61116119 .

Hawkins, T. R., Singh, B., Majeau-Bettez, G., and Strømman, A. H. (2013). Comparative environmental life cycle assessment of conventional and electric vehicles. Journal of Industrial Ecology, 17(1):53-64.

Heller, M. C. and Keoleian, G. A. (2003). Assessing the sustainability of the us food system: a life cycle perspective. Agricultural systems, 76(3):1007-1041.

Kahneman, D. (2011). Thinking, fast and slow. Farrar, Straus and Giroux.

Kallbekken, S. and Sælen, H. (2011). Public acceptance for environmental taxes: Self-interest, environmental and distributional concerns. Energy Policy, 39(5):2966-2973.

Kallbekken, S. and Sælen, H. (2013). 'nudging' hotel guests to reduce food waste as a win-win environmental measure. Economics Letters, 119(3):325-327.

Kant, I. (1870). Grundlegung zur metaphysik der sitten, volume 28. L. Heimann.

Kocher, M. G., Cherry, T., Kroll, S., Netzer, R. J., and Sutter, M. (2008). Conditional cooperation on three continents. Economics Letters, 101(3):175-178.

Kollmuss, A. and Agyeman, J. (2002). Mind the gap: why do people act environmentally and what are the barriers to pro-environmental behavior? Environmental Education Research, 8(3):239-260.

Kuhlemeier, H., Van Den Bergh, H., and Lagerweij, N. (1999). Environmental knowledge, attitudes, and behavior in dutch secondary education. The Journal of Environmental Education, 30(2):4-14.

Larrick, R. P. and Soll, J. B. (2008). The mpg illusion. Science, 320(5883):1593-1594.

Levine, D. K. (1998). Modeling altruism and spitefulness in experiments. Review of Economic Dynamics, 1(3):593-622.

McCallum, J. (1995). National borders matter: Canada-us regional trade patterns. The American Economic Review, 85(3):615-623. 
McPherson, M., Smith-Lovin, L., and Cook, J. M. (2001). Birds of a feather: Homophily in social networks. Annual Review of Sociology, 27(1):415-444.

Miettinen, T., Kosfeld, M., Fehr, E., and Weibull, J. W. (2017). Revealed preferences in a sequential prisoners' dilemma: A horse-race between five utility functions.

Moon, W., Florkowski, W. J., Brückner, B., and Schonhof, I. (2002). Willingness to pay for environmental practices: implications for eco-labeling. Land Economics, 78(1):88-102.

Moorman, C. (1996). A quasi experiment to assess the consumer and informational determinants of nutrition information processing activities: The case of the nutrition labeling and education act. Journal of Public Policy \& Marketing, 15(1):28-44.

Nyborg, K., Howarth, R. B., and Brekke, K. A. (2006). Green consumers and public policy: On socially contingent moral motivation. Resource and Energy Economics, 28(4):351-366.

Ogilvie, D., Foster, C. E., Rothnie, H., Cavill, N., Hamilton, V., Fitzsimons, C. F., and Mutrie, N. (2007). Interventions to promote walking: systematic review. BMJ, 334(7605):1204.

Pichert, D. and Katsikopoulos, K. V. (2008). Green defaults: Information presentation and proenvironmental behaviour. Journal of Environmental Psychology, 28(1):63-73.

Pindyck, R. S. (2013). Climate change policy: what do the models tell us? Journal of Economic Literature, 51(3):860-72.

Reisch, L. A. and Sunstein, C. R. (2016). Do europeans like nudges? Judgment and Decision Making, 11(4):310-325.

Roe, B., Teisl, M. F., Levy, A., and Russell, M. (2001). Us consumers' willingness to pay for green electricity. Energy Policy, 29(11):917-925.

Roy, P., Nei, D., Orikasa, T., Xu, Q., Okadome, H., Nakamura, N., and Shiina, T. (2009). A review of life cycle assessment (lca) on some food products. Journal of food engineering, 90(1):1-10.

Sallis, J., Bauman, A., and Pratt, M. (1998). Environmental and policy interventions to promote physical activity. American Journal of Preventive Medicine, 15(4):379-397.

Schultz, P. W., Nolan, J. M., Cialdini, R. B., Goldstein, N. J., and Griskevicius, V. (2007). The constructive, destructive, and reconstructive power of social norms. Psychological Science, 18(5):429434.

SFOE (2018). Statistique suisse de l'électricité 2017. Technical report, Swiss Federal Office of Energy SFOE.

Sierzchula, W., Bakker, S., Maat, K., and Van Wee, B. (2014). The influence of financial incentives and other socio-economic factors on electric vehicle adoption. Energy Policy, 68:183-194.

Sipes, K. N. and Mendelsohn, R. (2001). The effectiveness of gasoline taxation to manage air pollution. Ecological Economics, 36(2):299-309.

Sønderlund, A. L., Smith, J. R., Hutton, C. J., Kapelan, Z., and Savic, D. (2016). Effectiveness of smart meter-based consumption feedback in curbing household water use: Knowns and unknowns. Journal of Water Resources Planning and Management, 142(12):04016060. 
Steg, L. (2008). Promoting household energy conservation. Energy Policy, 36(12):4449-4453.

Sundt, S. and Rehdanz, K. (2015). Consumers' willingness to pay for green electricity: A metaanalysis of the literature. Energy Economics, 51:1-8.

Sunstein, C. R. and Reisch, L. A. (2014). Automatically green: Behavioral economics and environmental protection. Harv. Envtl. L. Rev., 38:127.

Taniguchi, A. and Fujii, S. (2007). Promoting public transport using marketing techniques in mobility management and verifying their quantitative effects. Transportation, 34(1):37.

Teisl, M. F., Roe, B., and Hicks, R. L. (2002). Can eco-labels tune a market? evidence from dolphinsafe labeling. Journal of Environmental Economics and Management, 43(3):339-359.

Thaler, R. H. and Sunstein, C. R. (2008). Nudge: Improving Decisions about Health, Wealth, and Happiness. Yale University Press.

Thalmann, P. (2004). The public acceptance of green taxes: 2 million voters express their opinion. Public Choice, 119(1-2):179-217.

Thilmany, D., Bond, C. A., and Bond, J. K. (2008). Going local: Exploring consumer behavior and motivations for direct food purchases. American Journal of Agricultural Economics, 90(5):13031309.

Vecchio, R. (2013). Determinants of willingness-to-pay for sustainable wine: Evidence from experimental auctions. Wine Economics and Policy, 2(2):85-92.

Vermeir, I. and Verbeke, W. (2006). Sustainable food consumption: Exploring the consumer "attitude-behavioral intention" gap. Journal of Agricultural and Environmental Ethics, 19(2):169194.

Vohs, K. D., Mead, N. L., and Goode, M. R. (2006). The psychological consequences of money. Science, 314(5802):1154-1156.

Willis, R. M., Stewart, R. A., Giurco, D. P., Talebpour, M. R., and Mousavinejad, A. (2013). End use water consumption in households: impact of socio-demographic factors and efficient devices. Journal of Cleaner Production, 60:107-115.

Wolf, H. C. (2000). Intranational home bias in trade. Review of economics and statistics, 82(4):555563.

Yi, K.-M. (2010). Can multistage production explain the home bias in trade? American Economic Review, 100(1):364-93.

Zhou, M. (2011). Intensification of geo-cultural homophily in global trade: Evidence from the gravity modelthe. Social Science Research, 40(1):193-209.

Zsóka, Á., Szerényi, Z. M., Széchy, A., and Kocsis, T. (2013). Greening due to environmental education? environmental knowledge, attitudes, consumer behavior and everyday pro-environmental activities of hungarian high school and university students. Journal of Cleaner Production, 48:126138. 


\section{Appendix A. Proofs}

\section{Appendix A.1 Proof of Theorem 1}

Theorem. For a given cooperation share of $\bar{x} \in[0,1]$, a homo moralis cooperates if and only if her degree of morality $\kappa_{i}$ is greater than the threshold $\kappa_{i}^{0}(\bar{x})$ with:

$$
\kappa_{i}^{0}(\bar{x})=\frac{I C_{i}(\bar{x})}{I C_{i}(\bar{x})+S B_{i}} \quad \in(0,1)
$$

Proof. For a given cooperation share of $\bar{x} \in[0,1]$, we know from Equation 3 that $u_{\kappa_{i}}(C, \bar{x})-$ $u_{\kappa_{i}}(D, \bar{x})=-\left(1-\kappa_{i}\right) \cdot I C_{i}(\bar{x})+\kappa_{i} \cdot S B_{i}$. Homo moralis cooperates if and only if $u_{\kappa_{i}}(C, \bar{x})-u_{\kappa_{i}}(D, \bar{x}) \geq$ 0 , i.e. if and only if $\kappa_{i} \geq I C_{i}\left(\bar{x} /\left(I C_{i}(\bar{x})+S B_{i}\right)\right.$ (Recall that by definition of social dilemmas $I C_{i}(\bar{x}>0$ and $\left.S B_{i}>0\right)$.

\section{Appendix A.2 Proof of Proposition 1}

Proposition. Let a population of homo moralis involved in a social dilemma such that the degrees of morality are independently drawn from the distribution $F($.$) . There exists an equilibrium cooperation-$ share $\bar{x}^{*} \in[0,1]$ such that $\bar{x}^{*}=1-\int_{i \in I} F\left(\kappa_{i}^{0}\left(\bar{x}^{*}\right)\right) d \mu$.

Proof. Let $G:[0,1] \rightarrow \mathbb{R}$ the function such that $G(\bar{x})=1-\int_{i \in I} F\left(\kappa_{i}^{0}(\bar{x})\right) d \mu-\bar{x}$. $F($.$) being$ a CDF, it has values in $[0,1]$. Therefore we have $G(0)=1-\int_{i \in I} F\left(\kappa_{i}^{0}(0)\right) d \mu \geq 0$ and $G(1)=$ $-\int_{i \in I} F\left(\kappa_{i}^{0}(1)\right) d \mu \leq 0$. Moreover, for all individuals $i \in I, \kappa_{i}^{0}:[0,1] \rightarrow(0,1)$ is continuous since individuals' payoffs are continuous in $\bar{x}$. Thus, $F\left(\kappa_{i}^{0}(\cdot)\right)$ is continuous and in turn $\int_{i \in I} F\left(\kappa_{i}^{0}(\cdot)\right) d \mu$ is also continuous. Consequently, $G(\cdot)$ is continuous. Hence, according to the intermediate value theorem, there exists $\bar{x}^{*} \in[0,1]$ such that $G\left(\bar{x}^{*}\right)=0$. 